\title{
Predicting Radiative Heat Transfer in Oxy-Methane Flame Simulations: An Examination of Its Sensitivities to Chemistry and Radiative Property Models
}

\author{
Hassan Abdul-Sater, ${ }^{1}$ Gautham Krishnamoorthy, ${ }^{1}$ and Mario Ditaranto ${ }^{2}$ \\ ${ }^{1}$ Department of Chemical Engineering, University of North Dakota, Harrington Hall Room 323, 241 Centennial Drive, \\ Grand Forks, ND 58202-7101, USA \\ ${ }^{2}$ SINTEF Energy Research, 7465 Trondheim, Norway
}

Correspondence should be addressed to Gautham Krishnamoorthy; gautham.krishnamoorthy@engr.und.edu

Received 21 August 2014; Revised 16 January 2015; Accepted 17 January 2015

Academic Editor: Dimitrios C. Rakopoulos

Copyright (C) 2015 Hassan Abdul-Sater et al. This is an open access article distributed under the Creative Commons Attribution License, which permits unrestricted use, distribution, and reproduction in any medium, provided the original work is properly cited.

\begin{abstract}
Measurements from confined, laminar oxy-methane flames at different $\mathrm{O}_{2} / \mathrm{CO}_{2}$ dilution ratios in the oxidizer are first reported with measurements from methane-air flames included for comparison. Simulations of these flames employing appropriate chemistry and radiative property modeling options were performed to garner insights into the experimental trends and assess prediction sensitivities to the choice of modeling options. The chemistry was modeled employing a mixture-fraction based approach, Eddy dissipation concept (EDC), and refined global finite rate (FR) models. Radiative properties were estimated employing four weighted-sum-of-gray-gases (WSGG) models formulated from different spectroscopic/model databases. The mixture fraction and EDC models correctly predicted the trends in flame length and $\mathrm{OH}$ concentration variations, and the $\mathrm{O}_{2}, \mathrm{CO}_{2}$, and temperature measurements outside the flames. The refined FR chemistry model predictions of $\mathrm{CO}_{2}$ and $\mathrm{O}_{2}$ deviated from their measured values in the flame with $50 \% \mathrm{O}_{2}$ in the oxidizer. Flame radiant power estimates varied by less than $10 \%$ between the mixture fraction and EDC models but more than $60 \%$ between the different WSGG models. The largest variations were attributed to the postcombustion gases in the temperature range $500 \mathrm{~K}-800 \mathrm{~K}$ in the upper sections of the furnace which also contributed significantly to the overall radiative transfer.
\end{abstract}

\section{Introduction}

Oxy-fuel combustion, where a fuel is burnt in a mixture of oxygen and recycled flue gas stream (containing primarily $\mathrm{CO}_{2}$ and $\mathrm{H}_{2} \mathrm{O}$ ), is a promising near-zero emission technology that can be adapted by existing and new electric power generation stations to mitigate the human impact on climate change [1]. To facilitate the retrofitting of existing combustors, oxidizer compositions and recycle ratios are currently being optimized with the aim of matching the flame temperature and wall radiative fluxes encountered during air-combustion by carefully taking into account the thermal effects associated with replacing $\mathrm{N}_{2}$ with $\mathrm{CO}_{2}$ [2]. Further, chemical effects associated with the participation of $\mathrm{CO}_{2}$ through the equilibrium: $\mathrm{CO}_{2}+\mathrm{H} \leftrightarrow \mathrm{CO}+\mathrm{OH}$, have also been identified
[3-7]. Consequently, the need to refine models for gas-phase chemistry and radiative properties that have previously been deemed to be accurate in computational fluid dynamic (CFD) simulations of combustion in air has garnered much attention in recent reviews $[8,9]$. This has led to the development and validation of gas-phase radiative property models in the form of weighted-sum-of-gray-gases (WSGG) coefficients based on different spectroscopic/model databases [10-13] and the refinement of kinetic parameters in previously proposed global kinetic mechanisms $[14,15]$ to improve their prediction accuracy in oxy-combustion scenarios [16-18]. Summarized in Table 1 are the results from CFD simulations of oxy-methane/natural gas combustion employing these refined chemistry and radiative property models. The studies indicate that while refined global kinetics, equilibrium based, 


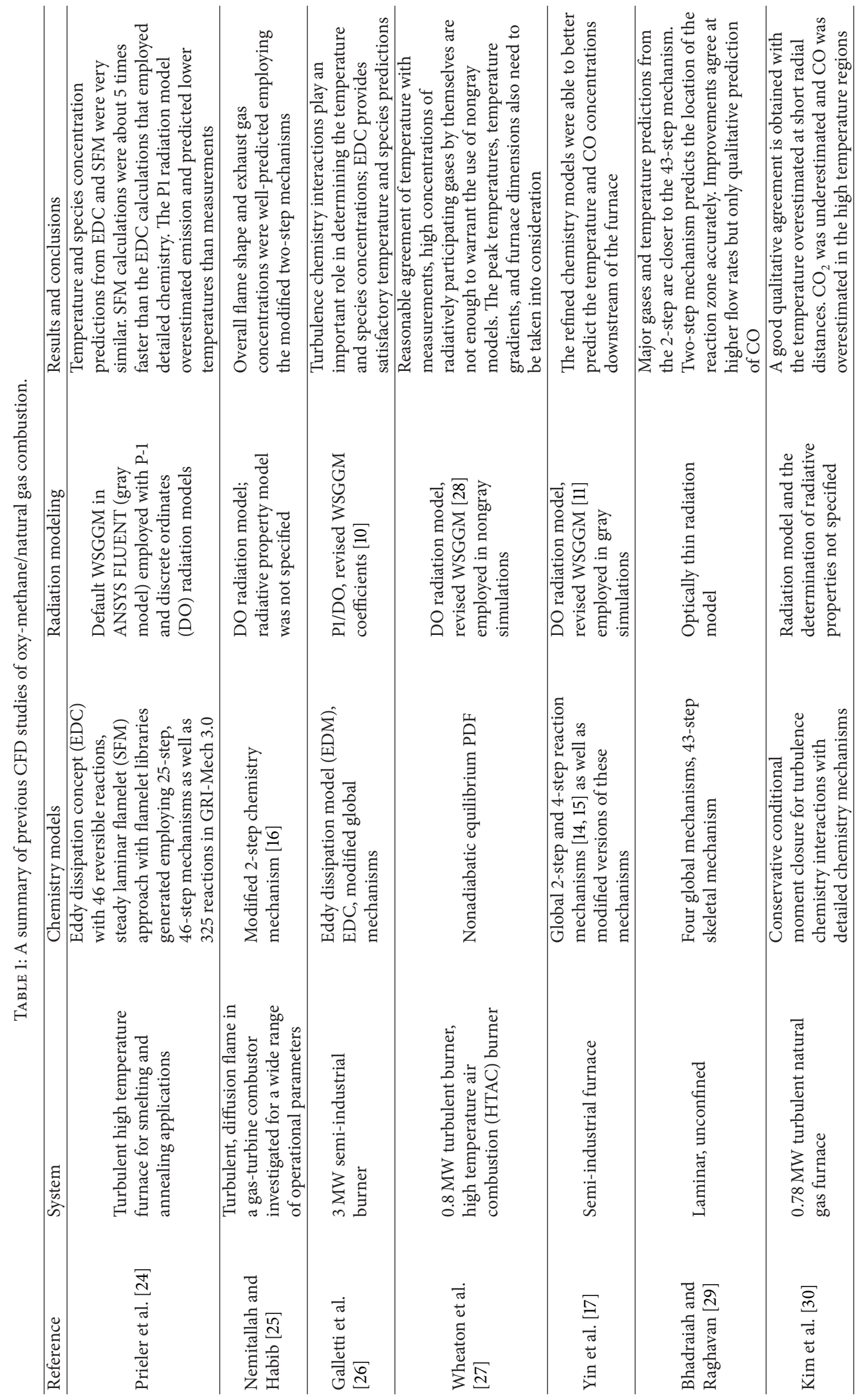




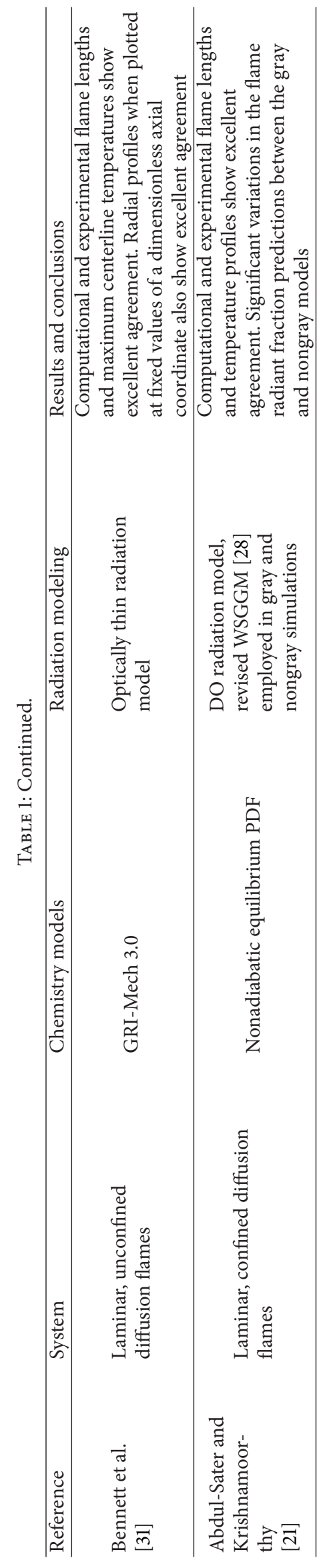


and reduced chemistry models were deemed to be accurate for predicting the temperature and major gas species concentrations in industrial applications, detailed chemistry models that account for dissociation were found to be necessary to accurately predict pollutant formation such as CO. Similarly, refined WSGG models for the gas-phase radiative properties were determined to be necessary to accurately model radiative transfer. However, a key step towards quantifying CFD prediction uncertainties from employing these refined models requires simultaneous measurements of species concentrations and temperature as well as radiative transfer variables under well-controlled, laminar flow conditions where measurement accuracies are quantified and minimized. To address this gap, experimental measurements of radiative transfer from oxy-methane flames at different oxidizer $\mathrm{O}_{2}-\mathrm{CO}_{2}$ dilution ratios were recently published [19]. Measurement accuracies and data correction were ensured by accounting for background wall emission and calculating the gas absorption at several axial locations. A cylindrical shape of the flame was assumed in their analysis and total radiative properties (absorption coefficients) were computed based on measured temperature and specie concentrations. These were employed in line-of-sight (1D) radiative transfer calculations performed using the statistical narrow band (SNB) model RADCAL [20]. A Monte Carlo ray tracing method was employed to determine the view factors of the various radiating elements seen by sensor. The $1 \mathrm{D}$ analysis showed that the peak value of the wall radiative fluxes was located at a height corresponding to $60-70 \%$ of the flame lengths and that the wall radiative fluxes declined rapidly above the length of the flame. Consequently, the temperature and specie concentrations measurements were also restricted to slightly above the flame lengths of the different flames. Further, Ditaranto and Oppelt [19] observed that while similar heat flux distributions and radiant fraction values were obtained for methane combustion in air as well as $35 \% \mathrm{O}_{2}-65 \% \mathrm{CO}_{2}$ oxidizers, these values increased with an increase in oxidizer $\mathrm{O}_{2}$ concentration. They attributed this increase to higher peak flame temperatures and enhanced soot formation rates. The goal of this study is to garner insights into these experimental observations through CFD simulations of the experimental conditions employing chemistry and radiative property models that have previously been deemed to be accurate for simulating these oxy-combustion scenarios (Table 1). Specifically, the goals of this study were to

(1) provide more complete descriptions of the flame shape and the spatial variations in temperature and gas concentrations throughout the furnace to increase the fidelity of the radiative transfer calculation compared to the previous study [19],

(2) quantify the contributions of the radiatively participating gases from the upper sections of the furnace to the overall radiative transfer to improve flame radiant fraction estimates since limited measurements were made in this region,

(3) understand the underlying cause for the observed experimental trends in flame radiant fraction variations with oxidizer compositions,
(4) assess the prediction sensitivities to the choice of modeling options employed in the simulations by considering three chemistry models and four radiative property models. Particular emphasis was placed on evaluating those chemistry models that can predict concentrations of minor species such as $\mathrm{H}, \mathrm{OH}$, and $\mathrm{O}$ which are critical towards determining the soot concentrations.

It is also important to recognize that the results reported in this study provide estimates of the wall radiative fluxes and total radiant power from oxy-methane flames in an environment where turbulence-radiation interactions (TRI) were minimized [21]. The importance of TRI was recognized in a recent study carried out by Becher et al. [22] where significant TRI caused considerable variability in radiative transfer predictions and precluded the determination of the most accurate radiative property model.

Experimental measurements from confined, laminar (Re 1404) methane flames in oxidizer compositions of $21 \%$ $\mathrm{O}_{2}-79 \% \mathrm{~N}_{2}, 35 \% \mathrm{O}_{2}-65 \% \mathrm{CO}_{2}$, and $50 \% \mathrm{O}_{2}-50 \% \mathrm{CO}_{2}$ are first reported in this study, followed by computational fluid dynamic (CFD) simulations of these flames. The gasphase radiative properties of $\mathrm{H}_{2} \mathrm{O}$ and $\mathrm{CO}_{2}$ were estimated employing different WSGGM for oxy-combustion scenarios that were formulated employing four different spectroscopic databases [10-13]. All of the WSGGM were implemented as user-defined functions (UDFs) and employed in conjunction with the CFD code ANSYS FLUENT [23]. In addition, the modeling of the gas-phase chemistry was undertaken employing the nonadiabatic extensions of the equilibrium probability density function (PDF) based mixture fraction model, a two-step global finite rate chemistry model with modified rate constants, and the Eddy dissipation concept (EDC) employing a 41-step detailed chemistry mechanism, models that have been deemed to be acceptable in oxy-combustion scenarios as listed in Table 1. In the numerical predictions of methane-air flames, the simulations were performed employing models appropriate for combustion in air.

\section{Methods}

2.1. Experimental Conditions. Figure 1 provides the geometric details of the furnace investigated in this study. The furnace consists of a cylindrical geometry with a fuel nozzle of diameter $5 \mathrm{~mm}$ and an oxidizer nozzle of diameter $100 \mathrm{~mm}$. These are enclosed in a stainless steel walled combustion chamber of diameter $350 \mathrm{~mm}$ and length $1000 \mathrm{~mm}$. The large dimension of the furnace relative to that of the flame minimized interaction and perturbation of the flow with the wall. The oxidizer gas was sent through a series of perforated plates to ensure uniform velocity distribution. The inside faces of the stainless steel walls of the reactor were coated with a blackbody paint of emissivity 0.98 . The temperature and gas concentration $\left(\mathrm{CO}_{2}, \mathrm{O}_{2}\right.$, and $\left.\mathrm{CO}\right)$ profiles around the flames were measured at different axial heights and in a radial direction from the wall until the vicinity of the outer limit of the flame is defined as when the CO concentration increased sharply. The gas was sampled with a quartz probe 


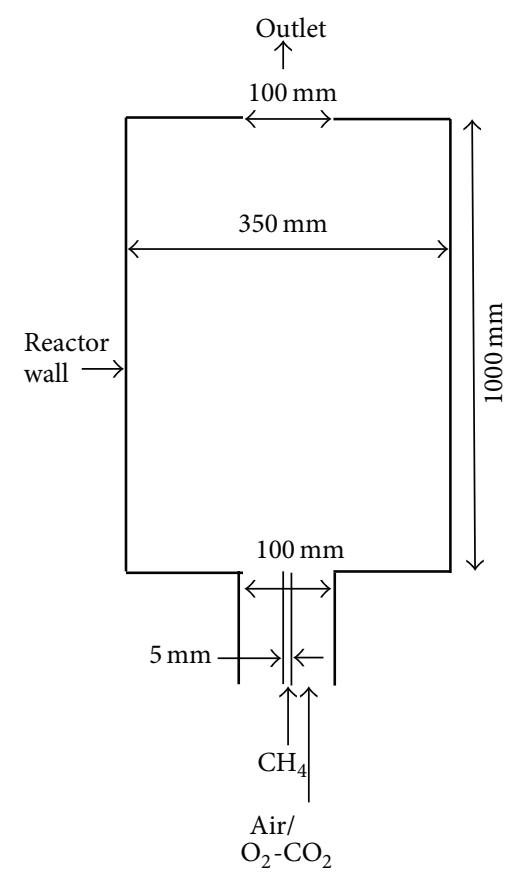

FIGURE 1: Geometric details of the furnace.

and analyzed with conventional gas analyzers and the temperature profiles were obtained by transversing radially four equally spaced $500 \mu \mathrm{m}$ fine bead thermocouples in the gas layer. Obtaining reliable species profiles within these small laboratory flames requires nonintrusive laser diagnostics, which were not applied in this study. The usage of the sampling probe was therefore been limited to regions where its measurements could be trusted.

The coflow velocity and fuel velocity were maintained at $0.25 \mathrm{~m} / \mathrm{s}$ and $4.6 \mathrm{~m} / \mathrm{s}$, respectively. The inlet temperature of the fuel was maintained at $288 \mathrm{~K}$ for the fuel densities to match the fuel inlet Reynolds number of 1404. The temperature of the $\mathrm{CO}_{2}$ supply was observed to be strongly dependent on the flow rate and the pressure in the liquid $\mathrm{CO}_{2}$ container due to its sensitivity to Joule-Thomson effects. Consequently, some temperature fluctuations in the coflow plenum were observed and an average coflow temperature of $288 \mathrm{~K}$ was therefore employed in the simulations. Although these variations in the coflow temperatures can strongly influence local flame extinction and lift-off characteristics, they were anticipated to play a minimal impact on the results and conclusions pertaining to radiative heat transfer that are reported in this study. For further details regarding the experimental conditions, the interested reader is referred to Ditaranto and Oppelt [19].

\subsection{CFD Modeling Approach}

2.2.1. Mesh and Flow Modeling. The CFD simulations were carried out using the commercial code ANSYS FLUENT [23]. The furnace was modeled in a $2 \mathrm{D}$ axisymmetric domain to take advantage of the symmetry of the problem. The geometry was meshed employing 30,700 hexahedral control volumes. Further refinement of the mesh to 263,000 control volumes did not change the results reported here. The flames in this study were determined to be in the buoyant regime since their laminar Froude numbers were less than unity [19]. Therefore, the pressure-velocity coupling was accomplished using the SIMPLEC algorithm [32] which we have determined from past experience to perform well in such buoyancy driven enclosure flows. The PRESTO [33] and QUICK [34] schemes were employed for the spatial discretization of the pressure and momentum terms, respectively, since hexahedral cells were employed in the calculations. Strong recirculation patterns were observed numerically and experimentally (via a decrease in gas temperature close to the walls as a result of downward flow). Therefore, obtaining steadystate converged results in the CFD simulations to compare against experimental measurements necessitated the utilization of the standard $k-\varepsilon$ turbulence model along with standard wall functions. The small flames examined in this study did not undergo appreciable spreading and were far away from the walls. Previous investigations of TRI in these flames [21] along with the very low values of the mixture fraction variance computed outside the flames in the simulations also reaffirm that the utilization of a turbulence model in the simulations is for numerical stability and to facilitate convergence only and has very little bearing on the results and conclusions reported in this study.

2.2.2. Radiation Modeling and Boundary Conditions. The radiation was modeled by solving the radiative transport equation (RTE) employing the discrete ordinate (DO) model. The angular discretization was carried out by employing a $3 \times 3$ theta $\times$ phi discretization. The adequacy of this angular resolution was established by determining that the reported variables did not change with any further increase in angular resolution. Unless otherwise mentioned (for instance, in the section where the sensitivity to the spectroscopic database employed in the WSGGM formulations is assessed) the radiative properties of the gas mixtures were all determined employing a recently proposed WSGG model [12] that is based on the SNB RADCAL. The WSGG model (with five graygases) accurately calculates the radiative properties of $\mathrm{CO}_{2}$ and $\mathrm{H}_{2} \mathrm{O}$ vapor mixtures that are encountered in scenarios encompassing methane, natural gas, or coal combustion under air-fired and oxy-fired conditions.

For boundary conditions for the radiation model, the stainless steel walls of the furnace were assigned an emissivity of 0.98 at the inside walls of the reactor [19]. The external walls (assigned an emissivity of 0.7 ) were assumed to radiate to the ambient air at $300 \mathrm{~K}$ and the furnace wall temperature was established by an energy balance between the net radiative and convective heat fluxes at the inside walls of the furnace and the net emission from the outside wall of the furnace. The nonavailability of the steady-state wall temperature measurements for all the flames necessitated the adopting of a physically realistic thermal boundary condition. The utilization of these boundary conditions has been validated in our previous study [21].

In order to investigate the sensitivity of the predictions to the spectroscopic/model databases employed in the WSGGM 
formulations, radiative transfer calculations were carried out in a fully coupled manner (with radiative transfer feedback to the energy equation) as well as in a decoupled manner by "freezing" the converged flow field that was obtained with the SNB RADCAL based WSGGM.

The decoupled simulations ensured that all the WSGGM calculations were performed on the same temperature and species concentration fields and any differences in the radiative source term predictions across the models do not translate to any further changes to the thermal field that can further magnify/minimize the differences in the radiative transfer predictions among the models. However, results from the coupled calculations confirmed that the impact of these differences in the radiative source term predictions among the WSGG models on the temperature field was minimal with maximum temperature variations generally less than $25 \mathrm{~K}$ across all flames. This is consistent with our observations in our previous study of these flames [21] where we noted significant differences in the volume integrated radiative source term predictions between the gray and five gray gas formulations of the same WSGG model but their impact on the temperature field was minimal. Therefore, results from the decoupled radiative transfer calculations are reported in this study for consistency in quantifying the differences among the WSGG models. Similar comparisons carried out by fully coupling the radiative transfer (by employing different WSGGM) and the flow field in all of our simulations are likely to result in only small changes to the results reported in this study while unaltering our overall conclusions.

The different WSGGM investigated in this study along with their model notations employed in this paper, the number of gray-gases (gg), and the spectroscopic data bases associated with their formulation are listed in Table 2.

2.2.3. Chemistry Modeling. Based on the recent studies summarized in Table 1, it is evident that the nonadiabatic extension of the equilibrium PDF based mixture fraction model, the Eddy dissipation concept (EDC), and global finite rate chemistry (FR) have been deemed to be appropriate for simulating the laminar to transitional oxy-methane flames investigated in this study. Therefore, simulations employing all three models were employed in this study to examine the variations in radiative transfer.

The FR chemistry modeling in this study was carried out employing the global kinetic parameters reported for the Westbrook and Dryer (WD) mechanism in Yin et al. [17]. The original unmodified kinetic parameters [14] were employed in the methane-air flame whereas the modified rate constants were employed in the oxy-methane flame simulations.

In a previous study [21], we had deemed the appropriateness of employing the nonadiabatic formulation of the equilibrium PDF based mixture fraction model (denoted as PDF) for these buoyant enclosure flames. The flame length and temperature predictions were found to agree well with the experimental measurements as well as trends at different oxidizer compositions and fuel inlet Reynolds numbers. In the mixture fraction approach, the instantaneous thermochemical state of a fluid is related to its mixture fraction and
TABLE 2: A summary of WSGGM investigated in this study.

\begin{tabular}{lcc}
\hline $\begin{array}{l}\text { Model notation } \\
\text { (number of gray gases) }\end{array}$ & Spectroscopic database & Reference \\
\hline Perry (5 gg) & $\begin{array}{l}\text { SNB RADCAL, Perry's } \\
\text { Chemical Engineering } \\
\text { Handbook }\end{array}$ & {$[12]$} \\
\hline EM2C $(5 \mathrm{gg})$ & EM2C SNB & {$[10]$} \\
\hline EWBM $(5 \mathrm{gg})$ & EWBM & {$[11]$} \\
\hline HITEMP 2010 $(5 \mathrm{gg})$ & HITEMP 2010 & {$[13]$} \\
\hline
\end{tabular}

its enthalpy. The benefits of this model are that, by assuming equal species diffusivities, the individual species conservation equations reduce to a single "sourceless" conservation equation for the mixture fraction as a result of the cancellation of the reaction source terms in the species equations due to elemental conservation. This enabled us to estimate the concentrations of minor species such as $\mathrm{OH}$ as well as get accurate predictions of the flame temperature in a computationally efficient manner without the need to resort to a detailed chemical mechanism that is applicable to oxy-combustion conditions. Under the assumption of chemical equilibrium, all thermochemical scalars (species fractions, density, and temperature) are uniquely related to the mixture fraction(s) and the value of each mass fraction, density, and temperature were determined from calculated values of mixture fraction, variance in mixture fraction, and the enthalpy. Twenty chemical species were considered in the equilibrium calculations $\left(\mathrm{CH}_{4}, \mathrm{C}_{2} \mathrm{H}_{2}, \mathrm{CH}_{3}, \mathrm{C}_{2} \mathrm{~N}_{2}, \mathrm{C}_{2} \mathrm{H}_{6}, \mathrm{C}_{2} \mathrm{H}_{4}, \mathrm{C}_{4} \mathrm{H}_{2}, \mathrm{C}_{3} \mathrm{H}_{3}, \mathrm{HNC}\right.$, $\mathrm{C}(\mathrm{s}), \mathrm{CO}, \mathrm{CO}_{2}, \mathrm{H}_{2} \mathrm{O}, \mathrm{OH}, \mathrm{N}_{2}, \mathrm{O}_{2}, \mathrm{H}, \mathrm{O}, \mathrm{HO}_{2}$, and $\left.\mathrm{H}_{2}\right)$. An assumed shape probability distribution function (PDF) was employed to describe any turbulence-chemistry interactions where the average value of the scalars is related to their instantaneously fluctuating values. In this study, the shape of the PDF was described by the beta function. 80 points in the mixture fraction and variance in mixture fraction space and 121 points in the enthalpy space were employed to carry out the interpolations and integrations within the PDF model.

In the EDC model, chemical reactions are assumed to take place in small turbulent structures referred to as fine scales. This is based on the turbulent energy cascade where large eddies break up into smaller eddies. The fine scales are then treated as constant pressure reactors where the combustion occurs. The concentration of species is then calculated by integrating the chemistry within these fine scales. This is undertaken by modeling the volume fraction of these fine structures in which the reactions take place, and the timescale for mass transfers from the fine structure to the surrounding fluid as functions of the turbulent kinetic energy $(k)$ and turbulent dissipation rates $(\varepsilon)$. However, the validity of the EDC model is limited to turbulent Reynolds numbers greater than $64[35,36]$. The turbulent Reynolds number is a function of the fluid density, distance to the near wall, turbulent kinetic energy, and the laminar viscosity of the fluid [23]. The turbulent Reynolds numbers were determined to be greater than 64 in the majority of the furnace and within the flames. However, there was a small localized region outside 

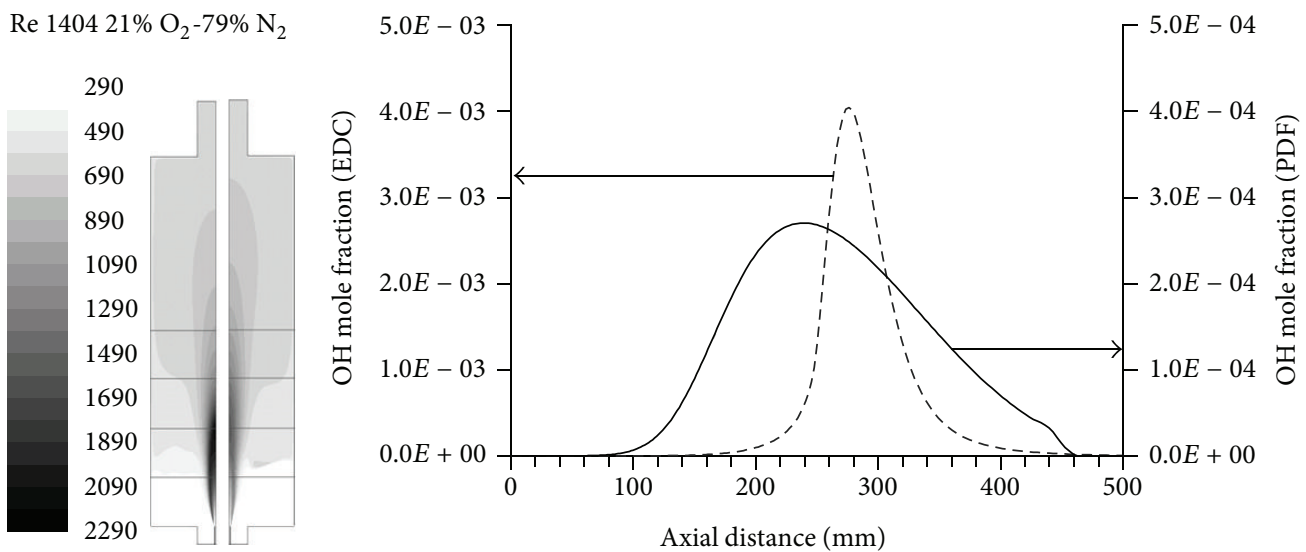

EDC PDF

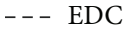

- PDF

(a)

Re $140435 \% \mathrm{O}_{2}-65 \% \mathrm{CO}_{2}$

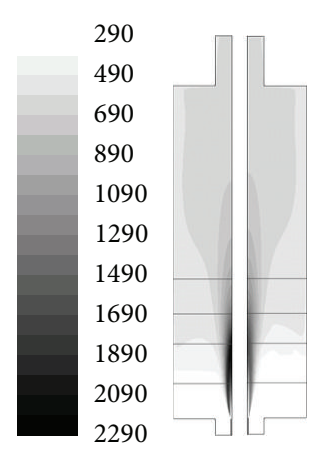

EDC PDF

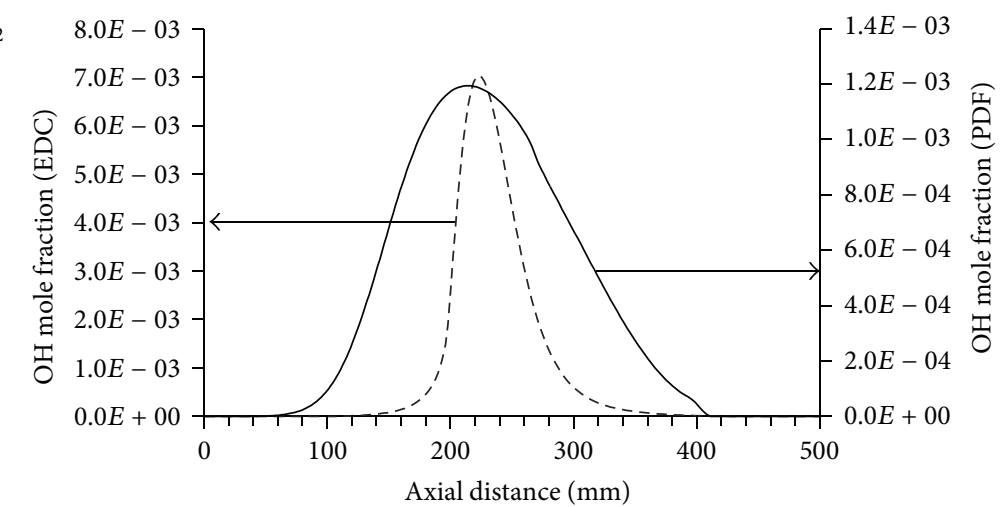

-.- EDC

- PDF

(b)
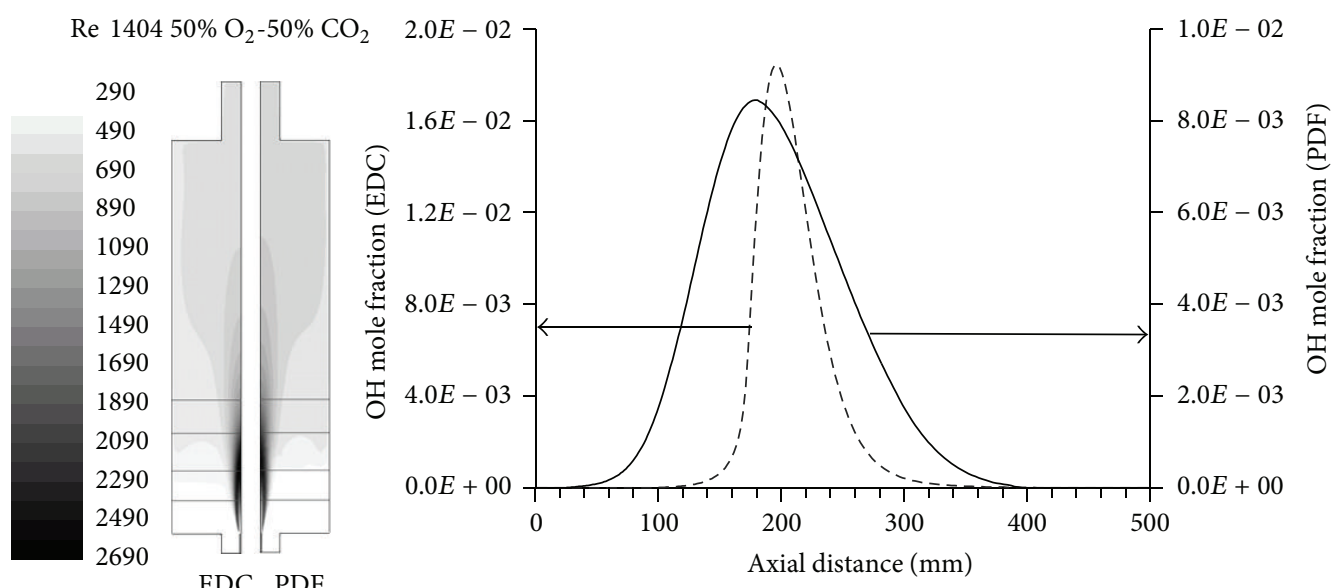

EDC PDF

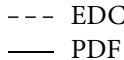

(c)

FIGURE 2: Temperature contours from the EDC and PDF model predictions and the corresponding axial variations in the OH concentrations for the three Re 1404 flames examined in this study. Oxidizer is (a) air, (b) $35 \% \mathrm{O}_{2}-65 \% \mathrm{CO}_{2}$, and (c) $50 \% \mathrm{O}_{2}-50 \% \mathrm{CO}_{2}$. 

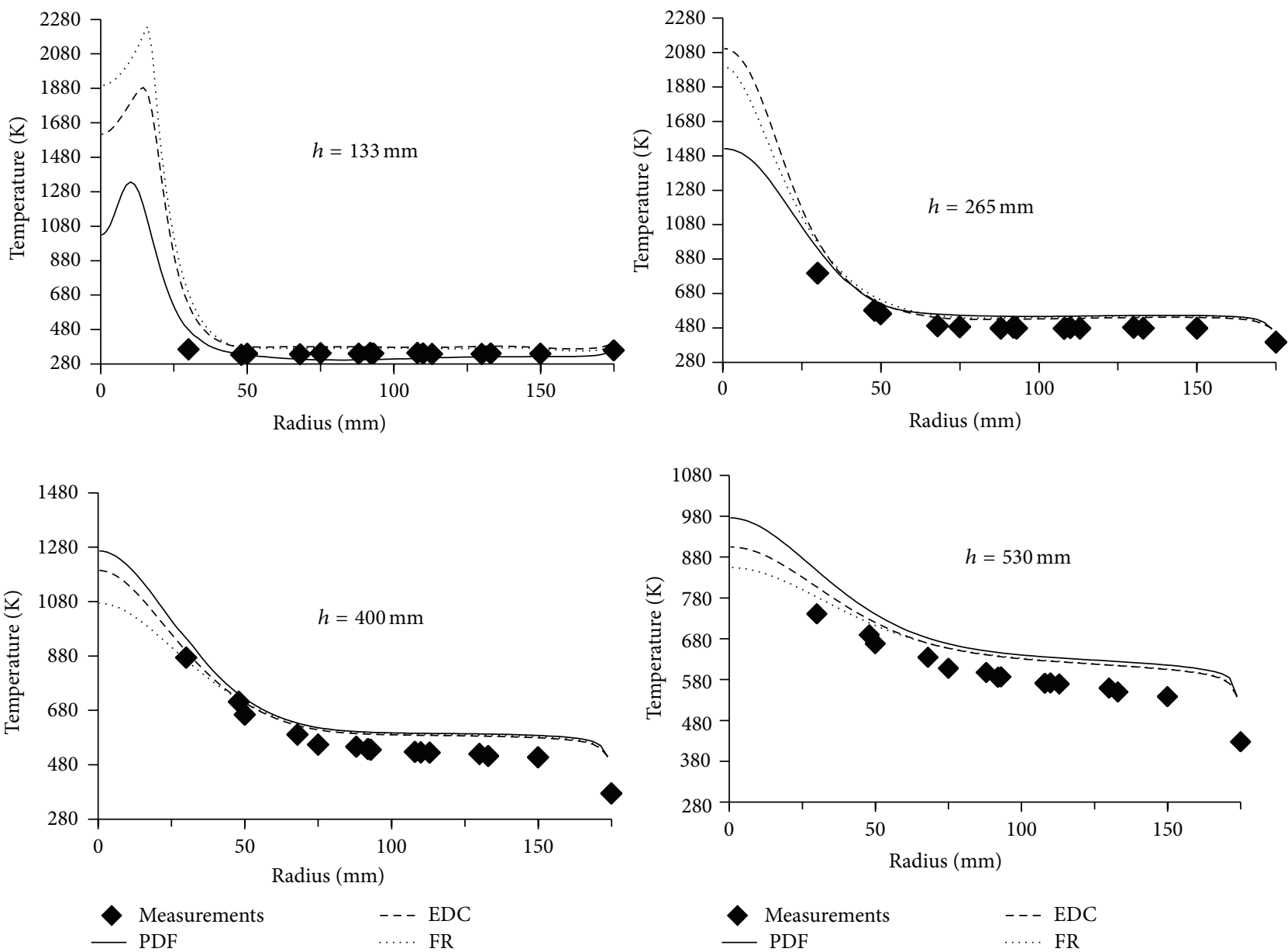

Figure 3: Radial temperature profiles at different axial locations for the Re 1404 air-methane flame.

the flame and the measurement locations near the bottom of the furnace corresponding to a recirculation zone near the walls, with temperature ranging from $300 \mathrm{~K}$ to $450 \mathrm{~K}$ where this requirement was not met. However, these were not expected to impact the results and conclusions reported in this study since the contribution of this region to the overall radiative transfer was minimal. In this study, the skeletal mechanism proposed by Smooke [37] for methane combustion which consists of 33 reactions and 17 species was used to represent the chemistry associated with the EDC model. The thermal and mass diffusion coefficients of the species were determined from kinetic theory and Soret diffusion was also accounted for in the calculations.

\section{Results and Discussion}

Radial measurements of temperature, $\mathrm{CO}_{2}$, and $\mathrm{O}_{2}$ outside the flame region were made at several axial locations in the three flames and are reported in this study. The CFD predictions are then compared against the experimental results.

3.1. Temperature. Temperature contours from the EDC and PDF model predictions and the corresponding axial variations in the $\mathrm{OH}$ concentrations for the three Re 1404 flames examined in this study are shown in Figure 2. The axial $\mathrm{OH}$ concentrations enable us to estimate the flame lengths [21]. The experimentally measured flame lengths in these flames were reported to be $482 \mathrm{~mm}, 434 \mathrm{~mm}$, and $373 \mathrm{~mm}$, respectively [19]. The temperature contours and the axial OH concentrations show that the flames resulting from the PDF model are longer (by $25-50 \mathrm{~mm}$ ) than the flames predicted from employing the EDC chemistry model. Consistent with experimental observations, both models predict a decrease in flame length, an increase in peak flame temperature, and an increase in $\mathrm{OH}$ concentration, with an increase in $\mathrm{O}_{2}$ concentration in the oxidizer stream.

Figures 3-5 compare the numerical temperature predictions against experimental measurements along the radial direction at four different axial locations for both air and oxycombustion cases. The axial centerline $(r=0)$ corresponds to the flame center. In Figure 3, predictions from all chemistry models are seen to agree well against experimental measurements. Variations between the models are more pronounced at lower axial and radial distances closer to the centerline axis. The FR chemistry model by virtue of limited dissociation predicts higher temperature than the equilibrium based mixture fraction and EDC approaches. The EDC based approach incorporates multiple minor species that may have 

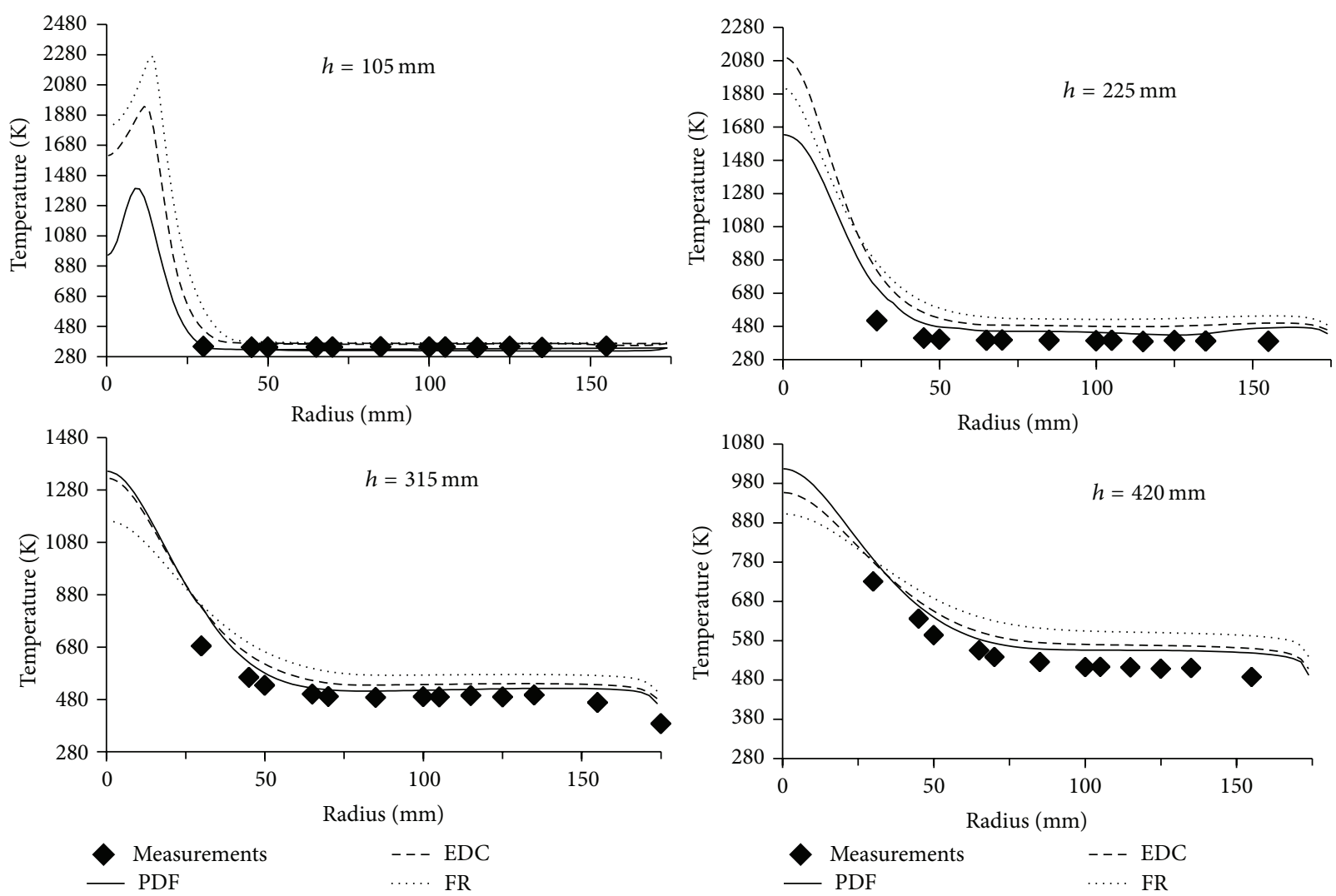

FIgURE 4: Radial temperature profiles at different axial locations for the Re 1404 oxy-methane flame $\left(35 \% \mathrm{O}_{2}-65 \% \mathrm{CO}_{2}\right)$.

slower rates of formation and are not yet at their equilibrium concentrations at smaller residence times or lower axial distances. Hence, its temperature predictions are lower than those from the FR model and higher than the equilibrium PDF approach at lower axial distances in all three flames. As noted in Figure 2, the flame length (or the point where the stoichiometric mixture fraction is reached) is displaced further downstream in the PDF model calculations when compared to the EDC model calculations. Therefore, at lower axial locations the mixture fraction is higher in the PDF model predictions when compared against the EDC model predictions. This along with the fact that the PDF model assumes complete dissociation with heat loss (nonadiabatic) results in cooler temperatures at those lower axial locations. However, predictions from all models start converging to the same values at large residence times in the postflame zone when all of the combustion products attain equilibrium, as well as in the fuel lean regions outside the flame. This agreement between the temperature measurements and predictions near the wall further affirms the adequacy of the wall boundary conditions and the wall temperatures predicted by the simulations. The trends in the temperature predictions in the oxy-flames shown in Figures 4 and 5 are consistent with those observed in Figure 3. In the oxy-flames, the three chemistry models converge to the same temperature values at lower axial distances since the flame lengths get shorter with an increase in oxygen concentration in the oxidizer stream [19].
3.2. $\mathrm{CO}_{2}$. Figures $6-8$ compare the numerical variations in $\mathrm{CO}_{2}$ concentrations (mol\% dry basis) against experimental measurement along the radial direction at four different axial locations for both air and oxy-fuel combustion cases. Corresponding to the temperature plot, the FR chemistry model overpredicts the $\mathrm{CO}_{2}$ at lower axial distances and therefore at small flame residence times whereas the EDC and equilibrium mixture fraction models converge to the correct value at large residence times. At lower axial distances (or small residence times) the PDF model due to the assumption of complete dissociation predicts lower $\mathrm{CO}_{2}$ concentrations when compared against the FR and EDC chemistry models. The finite rate chemistry model with the modified WD rate constants, while performing well in the $35 \% \mathrm{O}_{2}-65 \% \mathrm{CO}_{2}$ oxy-flame, overpredicts the $\mathrm{CO}_{2}$ concentrations in the $50 \%$ $\mathrm{O}_{2}-50 \% \mathrm{CO}_{2}$ oxy-flame. This is likely due to the fact that the refined kinetic parameters employed in the global finite rate chemistry model have not been validated for flames where oxygen concentration in the oxidizer stream was as high as $50 \%$.

3.3. $\mathrm{O}_{2}$. Figure 9 shows the predicted radial variations in the $\mathrm{O}_{2}$ concentrations (mol\% dry basis) against experimental measurements. While reasonable agreement with the experimental predictions is obtained from the equilibrium mixture fraction approach and the EDC model in all three flames, the finite rate chemistry model with the modified WD rate 

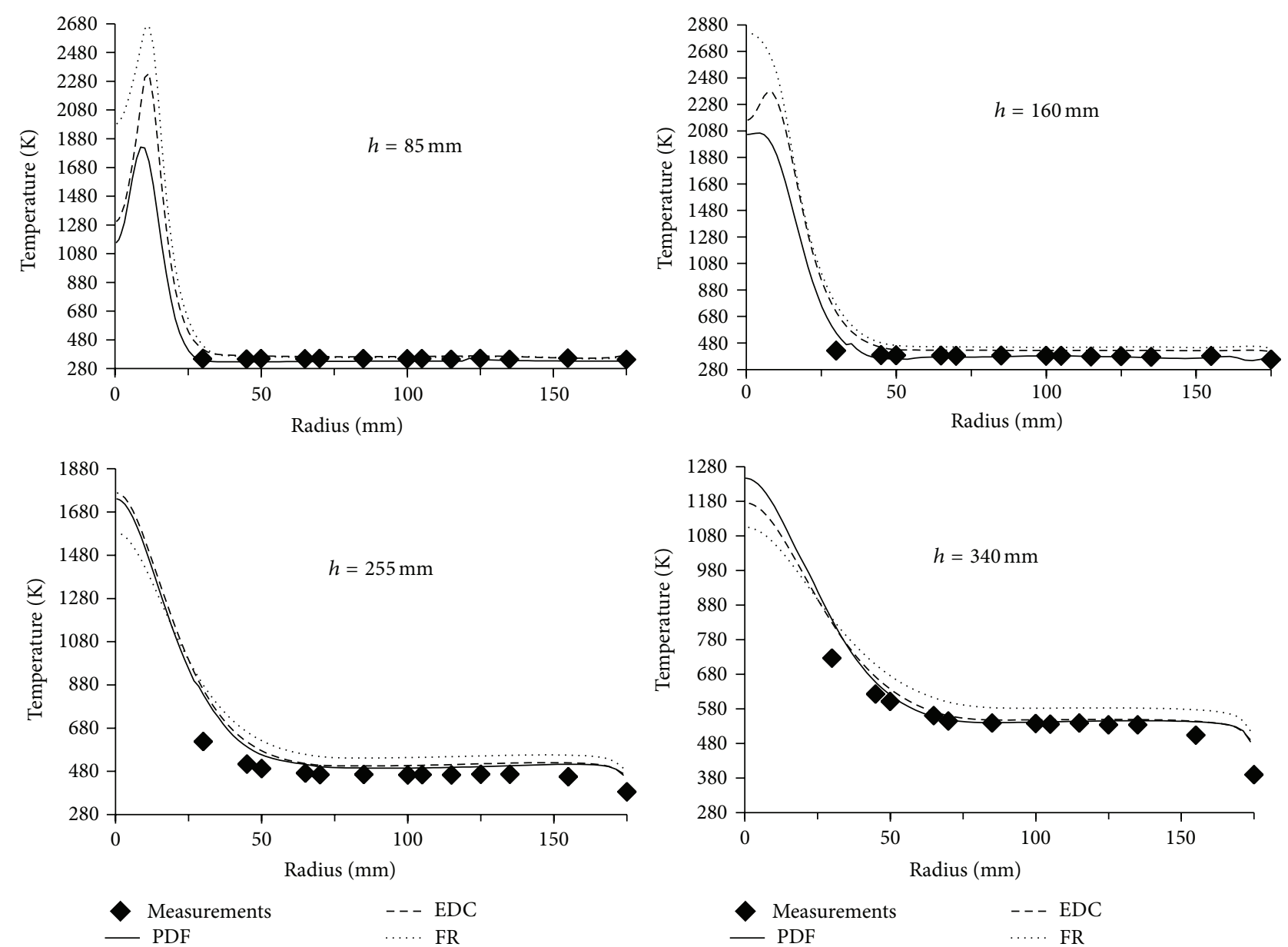

FIgURE 5: Radial temperature profiles at different axial locations for the Re 1404 oxy-methane flame $\left(50 \% \mathrm{O}_{2}-50 \% \mathrm{CO}_{2}\right)$.

constants, while performing well in the $35 \% \mathrm{O}_{2}-65 \% \mathrm{CO}_{2}$ oxy-flame, underpredicts the $\mathrm{O}_{2}$ concentrations in the $50 \%$ $\mathrm{O}_{2}-50 \% \mathrm{CO}_{2}$ oxy-flame.

3.4. Effect of WSGGM Spectroscopic/Model Database. The radiative source term $(-\nabla \cdot \mathbf{q}(\mathbf{r}))$ describes the conservation of radiative energy within a control volume and goes into the total energy ( $E$ ) equation (see (1)), thereby coupling radiation with the other physical processes that occur in a combustion simulation [23]:

$$
\begin{aligned}
\frac{\partial}{\partial t} & (\rho E)+\nabla \cdot(\vec{v}(\rho E+p)) \\
& =\nabla \cdot\left(\Gamma \nabla T-\sum_{j} h_{j} \vec{J}_{j}+(\overline{\bar{\tau}} \vec{v})\right)+S_{h}-\nabla \bullet q .
\end{aligned}
$$

On the left hand side of (1), $E$ is the total energy and $p$ is the pressure. The first three terms on the right hand side represent the "diffusion" contributions to the total energy equation. " $\Gamma$ " the thermal conductivity along with the temperature " $T$ " represents the conduction contribution. " $h$ " and "J" represent the enthalpy and diffusion flux of species $j$ and represent energy transfer due to species diffusion, and " $\tau$ " and " $v$ " are the fluid shear stress and velocity, respectively, and represent the viscous dissipation contribution. " $S_{h}$ " and " $-\nabla \cdot \mathbf{q}(\mathbf{r})$ " are volumetric source terms representing the energy released during chemical reaction and the energy absorbed/emitted through radiative exchange, respectively.

If " $k$ " represents the absorption coefficient within a control volume, " $G$ " the total incident radiation, and $I_{b}$ the black body emissive power, then the radiative source term $-\nabla \cdot \mathbf{q}(\mathbf{r})$ can be computed by summing the contributions over all bands " $i$ " as

$$
-\nabla \cdot \mathbf{q}(\mathbf{r})=\sum_{i=\text { band }} k_{i}(\mathbf{r})\left(G_{i}(\mathbf{r})-4 \pi I_{b, i}(\mathbf{r})\right) .
$$

$G$, the incident radiation in (2), is calculated by integrating the directional intensities $(I)$ associated with the wavelength band " $i$ " over all directions as

$$
G_{i}(\mathbf{r})=\int_{4 \pi} I_{i}(\mathbf{r}, \hat{\mathbf{s}}) d \mathbf{\Omega} .
$$

A negative value of the radiative source term corresponds to a net emission. The volume integral of the radiative source term therefore is a measure of the total radiative energy lost by the flame as a result of emission and absorption and is therefore employed to determine the flame radiant fractions 

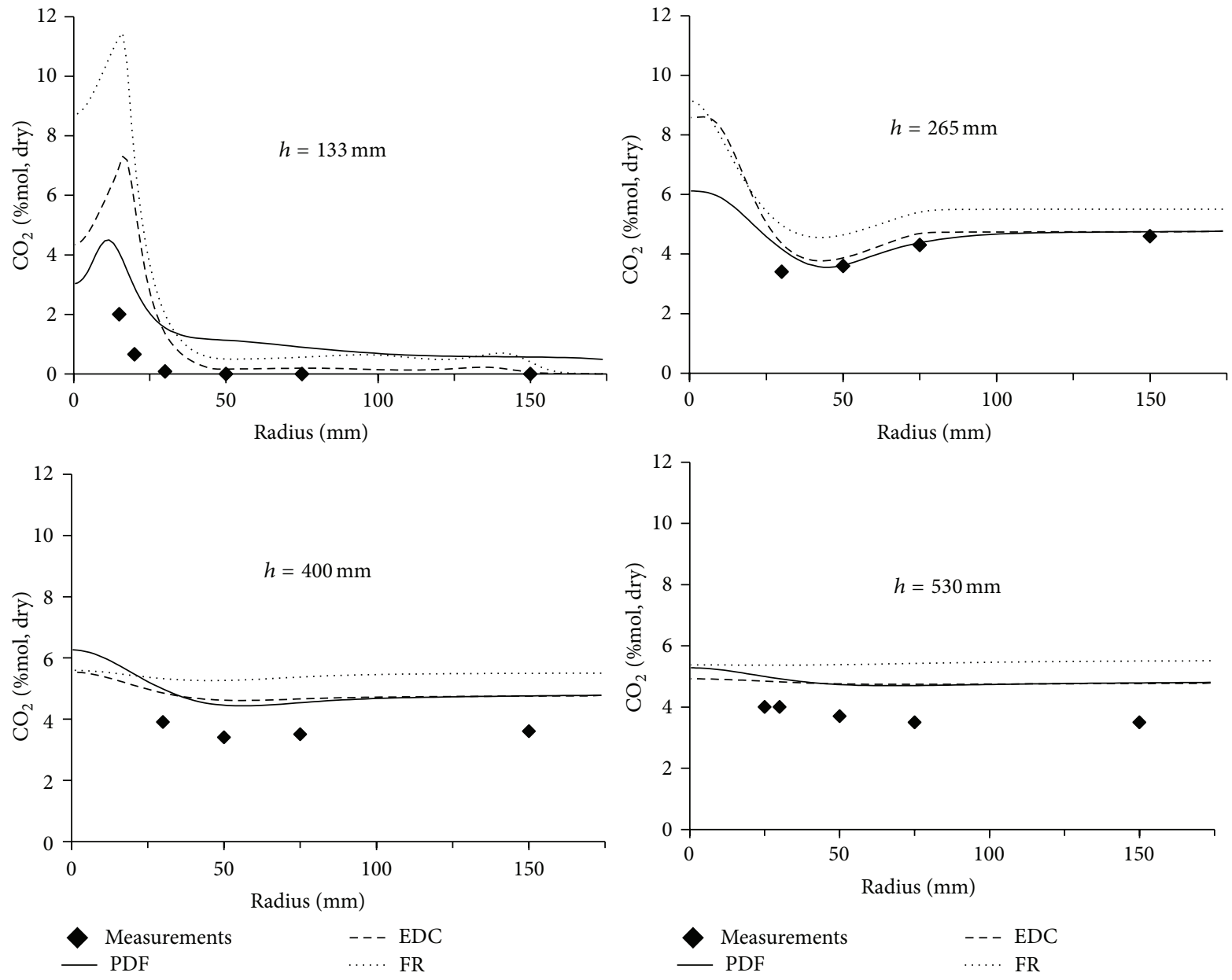

FIGURE 6: Radial $\mathrm{CO}_{2}$ profiles at different axial locations for the Re 1404 air-methane flame.

TABLE 3: Volume integrated radiative source (in W) $\left(Q_{R}\right)$ for the flames investigated in this study (sensitivity to WSGG models).

\begin{tabular}{|c|c|c|c|c|c|}
\hline & EWBM (5 gg) & Perry (5 gg) & EM2C (5 gg) & HITEMP 2010 (5 gg) & Max \% variation \\
\hline \multicolumn{6}{|c|}{ PDF, Re 1404} \\
\hline $21 \% \mathrm{O}_{2}$ & -801 & -822 & -889 & -1089 & -36 \\
\hline $35 \% \mathrm{O}_{2}$ & -740 & -755 & -1189 & -788 & -61 \\
\hline $50 \% \mathrm{O}_{2}$ & -813 & -781 & -1277 & -842 & -64 \\
\hline \multicolumn{6}{|c|}{ PDF, Re 2340} \\
\hline $21 \% \mathrm{O}_{2}$ & -1871 & -1889 & -2061 & -2518 & -35 \\
\hline $35 \% \mathrm{O}_{2}$ & -2049 & -1724 & -2804 & -2210 & -63 \\
\hline $50 \% \mathrm{O}_{2}$ & -2146 & -1794 & -2855 & -2245 & -59 \\
\hline
\end{tabular}

(by dividing the volume integral of (2) by the product of fuel heating value and mass flow rate). Table 3 compares the volume integrated radiant source (or the magnitude of radiant power) predicted by the different WSGGM (by not varying the chemistry model). The fuel inlet Reynolds numbers and the chemistry model employed in the calculations are indicated in bold. The volume integrated radiant source or flame radiant power $\left(Q_{R}\right)$ was computed as

$$
Q_{R}=-\iiint_{\mathrm{V}} \nabla \cdot \mathbf{q}(\mathbf{r}) d V
$$



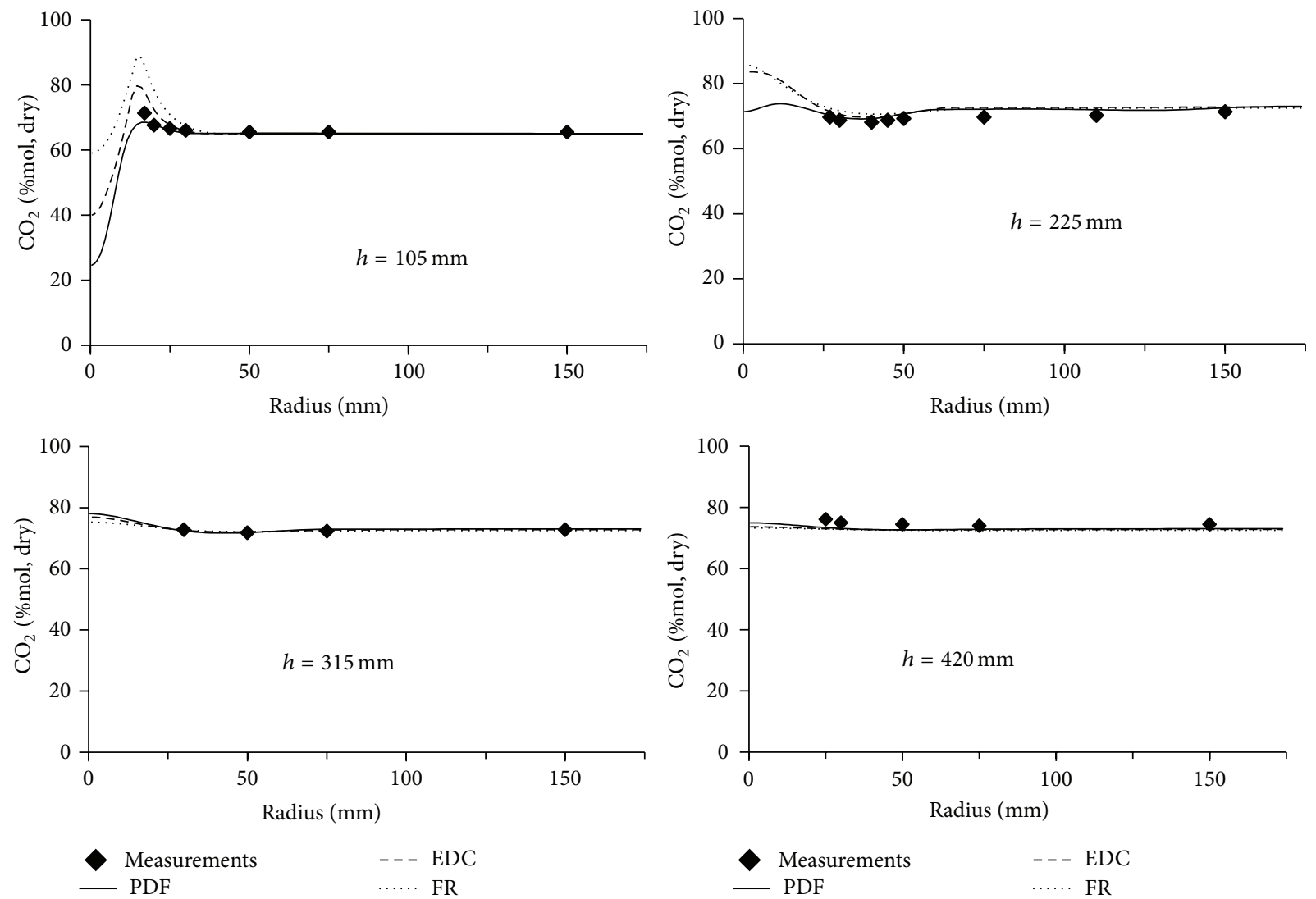

Figure 7: Radial $\mathrm{CO}_{2}$ profiles at different axial locations for the Re 1404 oxy-methane flame $\left(35 \% \mathrm{O}_{2}-65 \% \mathrm{CO}_{2}\right)$.

The maximum percentage variations in $Q_{R}$ for all the flames are also shown in Table 3 at two different fuel inlet Reynolds numbers. The simulations reported in Table 3 were all carried out using the PDF chemistry model. The maximum percentage variation for each flame was computed as

$$
\frac{Q_{R, \text { high }}-Q_{R, \text { low }}}{Q_{R \text {,high }}} \times 100 \text {. }
$$

The maximum variations in $Q_{R}$ are observed in the oxyflames (greater than 60\%) and these are seen to be independent of the fuel inlet Re. While previous studies have attributed high accuracies to both the EM2C (5 gg) [38] and the HITEMP 2010 (5 gg) models [13], Table 3 shows significant differences in the predictions between these two models in both methane-air flames and the oxy-methane flames.

3.5. Effect of Chemistry Model. Table 4 compares the corresponding variations in $Q_{R}$ for the different chemistry models. The radiative properties for all the flames reported in Table 4 were computed employing the Perry $(5 \mathrm{gg})$ model. The FR chemistry model by virtue of predicting high temperatures as a result of limited dissociation predicts significantly higher $Q_{R}$ values than the EDC and PDF models. However, despite differences in the flame lengths and the temperature predictions at lower axial locations between the EDC and PDF models, $Q_{R}$ varies by less than $10 \%$ between the chemistry models.
TABLE 4: Volume integrated radiative source (in $W)\left(Q_{R}\right)$ for the flames investigated in this study (sensitivity to chemistry models).

\begin{tabular}{lcccc}
\hline & \multicolumn{4}{c}{ Re 1404, Perry (5 gg) } \\
& FR & EDC & PDF & Max \% variation \\
\hline $21 \% \mathrm{O}_{2}$ & -1041 & -871 & -822 & $-\mathbf{2 7}$ \\
$35 \% \mathrm{O}_{2}$ & -1069 & -769 & -755 & $\mathbf{- 4 2}$ \\
$50 \% \mathrm{O}_{2}$ & -1109 & -867 & -781 & $\mathbf{- 4 2}$ \\
\hline
\end{tabular}

3.6. Effect of Soot. The variations in the radiative source term predictions among the WSGG models (Table 3) made it difficult to numerically ascertain the trends in radiant fraction variations with the changes in the oxygen concentration in the oxidizer stream. The EWBM (5 gg) and Perry (5 gg) models in general predicted similar radiant fractions at all three oxidizer compositions (Tables 3 and 4). These results are generally in agreement with the observations of Ditaranto and Oppelt [19] who observed similar heat flux distributions and radiant fraction values for combustion in air as well as $35 \% \mathrm{O}_{2}-65 \% \mathrm{CO}_{2}$ oxidizers. The EM2C (5 gg) model predicted a significant increase in radiant fraction with the increase in oxygen composition in the oxidizer stream whereas the HITEMP 2010 (5 gg) model predicted a decrease in radiant fraction in the oxy-flames. 

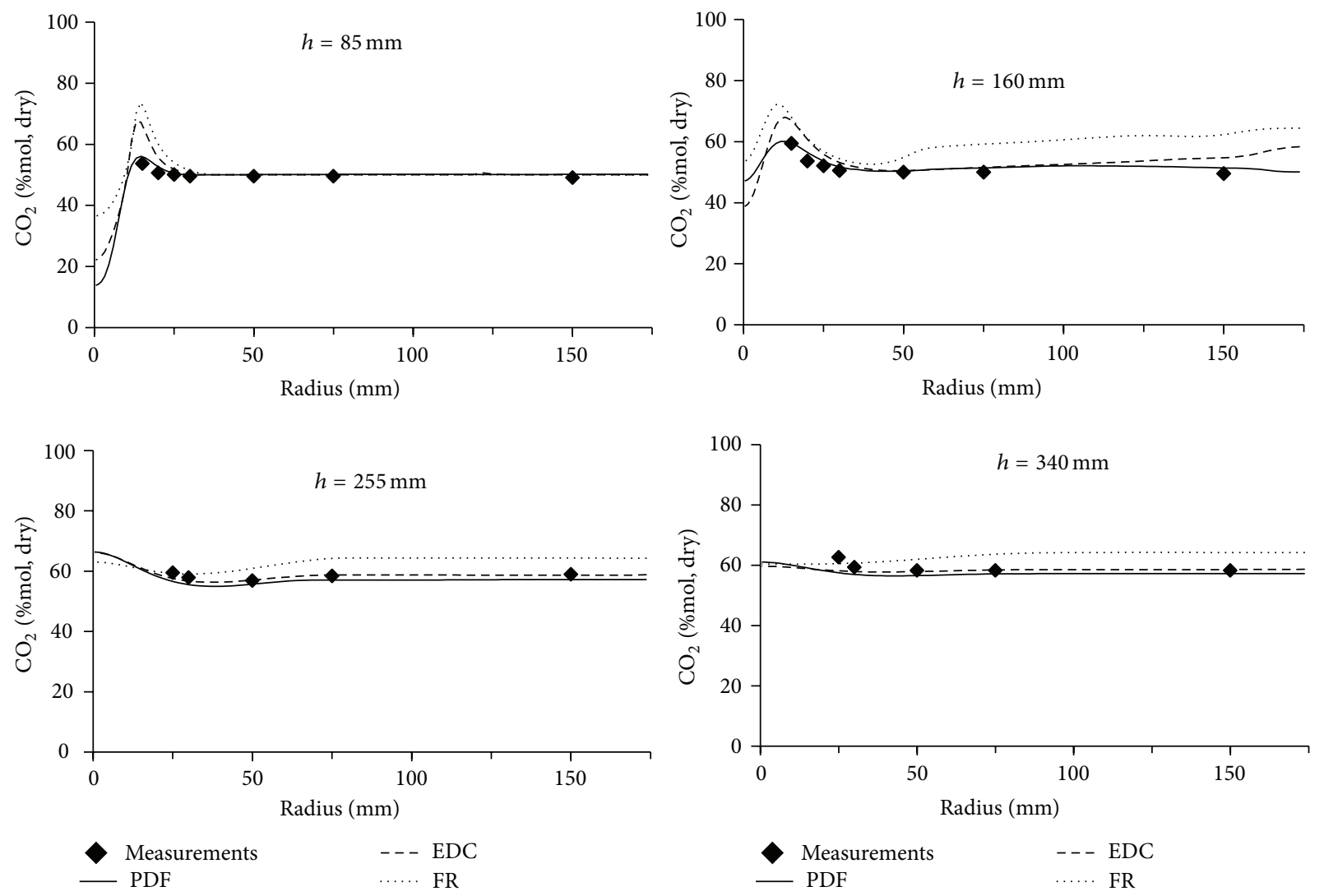

FIGURE 8: Radial $\mathrm{CO}_{2}$ profiles at different axial locations for the Re 1404 oxy-methane flame $\left(50 \% \mathrm{O}_{2}-50 \% \mathrm{CO}_{2}\right)$.

However, Ditaranto and Oppelt [19] observed an increase in radiant fraction with the oxygen composition in the oxidizer (beyond 35\%) and attributed this to the increase in the soot inception rates at higher oxygen concentrations, resulting in higher soot concentrations and therefore higher soot emissions in the oxygen-rich flames [39]. In order to investigate this effect, the implementation of the Moss-Brookes soot model [40] in ANSYS FLUENT that has mainly been developed and validated for methane flames was employed to predict the soot volume fractions in the different flames. We have previously reported the soot volume fraction predictions employing the Perry ( $5 \mathrm{gg}$ ) WSGG at Reynolds numbers 468 and 2340 for several oxidizer compositions [21]. In this study, similar calculations were performed employing the EDC chemistry model. Contrary to the deductions of Ditaranto and Oppelt [19], we found that the peak soot volume fraction decreases with higher oxygen concentrations in the oxidizer possibly due to the increased oxidation of soot by the $\mathrm{OH}$ radicals. The peak soot concentrations values in the Re 1404 flames during combustion in air, $35 \% \mathrm{O}_{2}-65 \% \mathrm{CO}_{2}$ and $50 \%$ $\mathrm{O}_{2}-50 \% \mathrm{CO}_{2}$, were on the order of $10^{-2}, 10^{-3}$, and $10^{-4} \mathrm{ppm}$, respectively. Consequently, due its low concentrations, the presence of soot was observed to have a negligible effect on the flame radiant power predictions. Soot formation rates however have been observed to increase with increase in Reynolds numbers due to shorter residence times and incomplete mixing. The effects of soot on radiative transfer during methane combustion are in general agreement with our previous observations from simulations of methane pool fires where mixing is incomplete. Even at a maximum soot volume fraction of $0.1 \mathrm{ppm}$, less than $5 \%$ change in the flame radiant fraction predictions was observed [41]. Nevertheless, the effect of soot needs further investigation at higher fuel jet velocities.

3.7. Wall Incident Radiative Fluxes. Figure 10 shows the variations in the incident radiative fluxes along the walls of the furnace (in the axial direction) for two oxy-flames $\left(35 \% \mathrm{O}_{2}-65 \%\right.$ $\mathrm{CO}_{2}$ ) from Table 3. The fuel inlet Re and chemistry model employed in the calculations are also indicated in the title. The wall incident radiative fluxes (that would be measured by a sensor for instance) were determined through an integration of the normal component of the directional intensities over a hemisphere as

$$
\mathbf{q}(\mathbf{r})=\int_{4 \pi} I(\mathbf{r}, \hat{\mathbf{s}}) \hat{\mathbf{s}} d \mathbf{\Omega}
$$

The variations in $Q_{R}$ among the WSGGM reported in Table 3 translate to corresponding variations in the wall incident radiative fluxes through the radiative energy balance on this furnace. The radiative energy balance within this furnace implies that the integral of the radiative source term $\left(Q_{R}\right)$ within the furnace volume is equal to the surface integral 

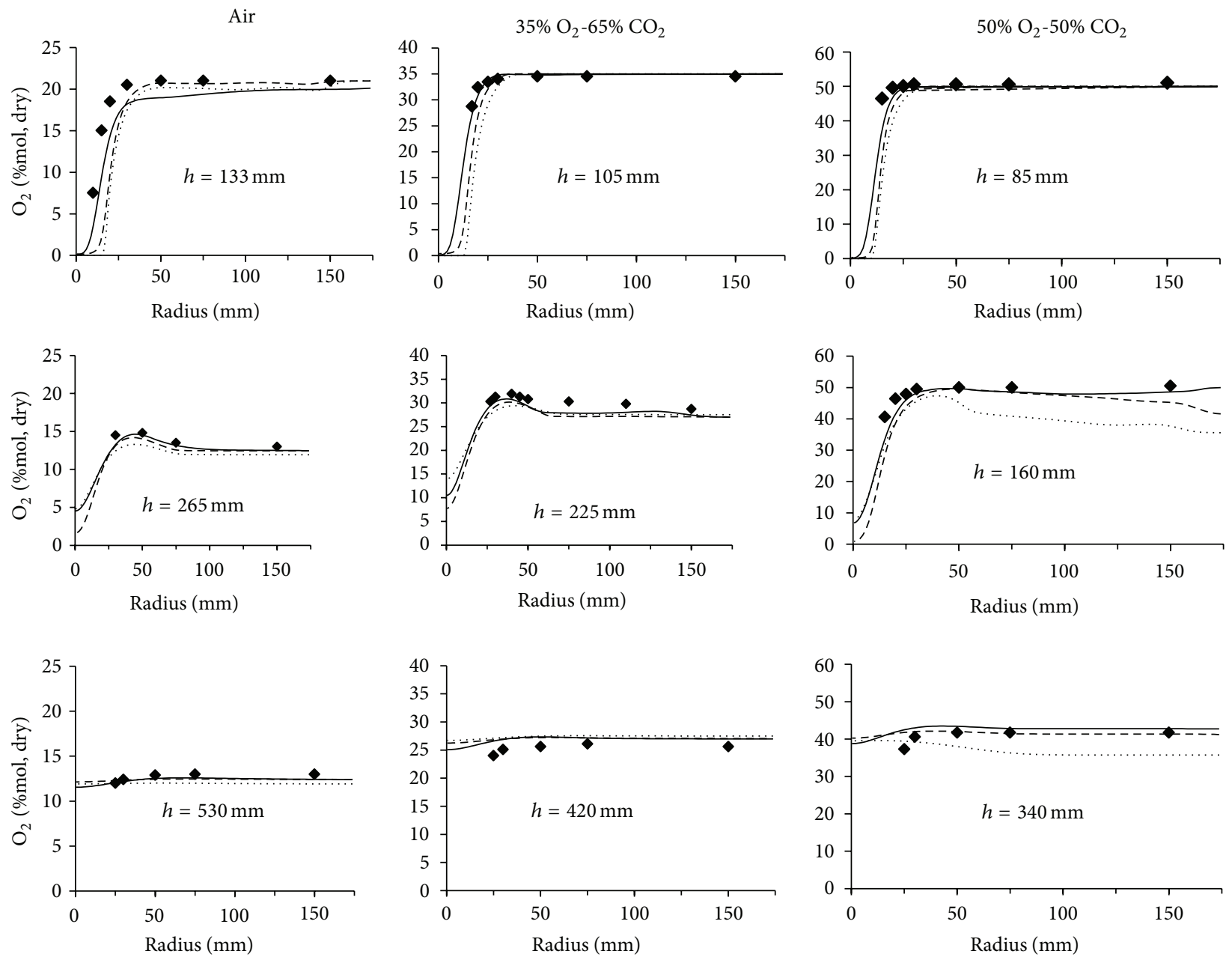

Measurements - - EDC PDF

FR

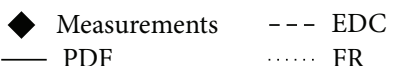

Measurements - - - EDC PDF

FIgURE 9: Radial $\mathrm{O}_{2}$ profiles at different axial locations for the Re 1404 air and oxy-flames investigated in this study.

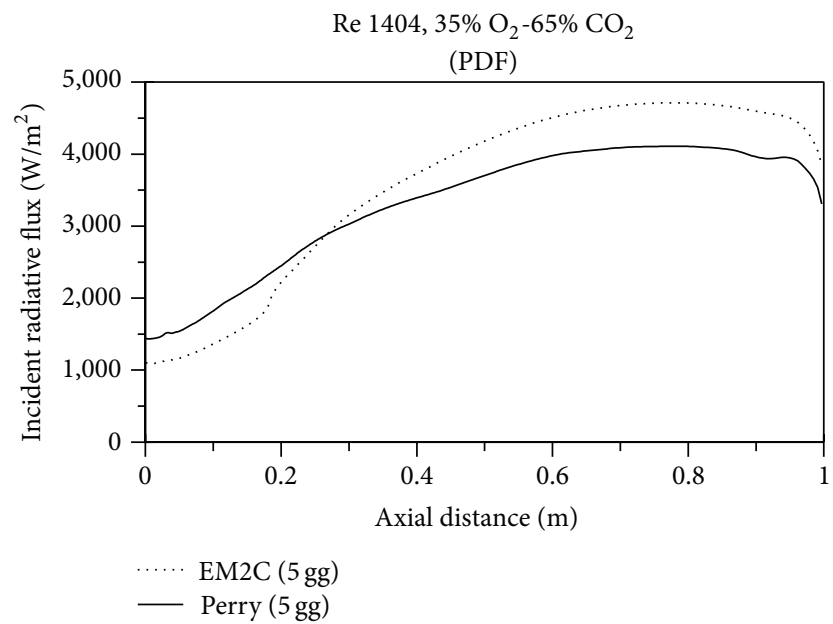

(a)

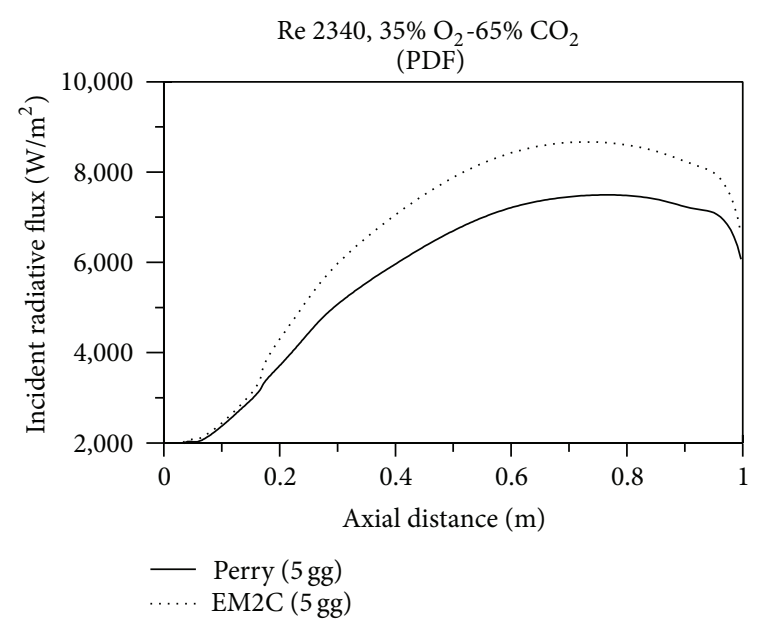

(b)

FIGURE 10: Variations in the incident radiative fluxes (in W/ $\mathrm{m}^{2}$ ) at the wall predicted by the different WSGG models: (a) Re 1404, oxy-methane flame (35\% $\left.\mathrm{O}_{2}-65 \% \mathrm{CO}_{2}\right)$; (b) Re 2340, oxy-methane flame $\left(35 \% \mathrm{O}_{2}-65 \% \mathrm{CO}_{2}\right)$. 
$\operatorname{Re} 1404,21 \% \mathrm{O}_{2}$

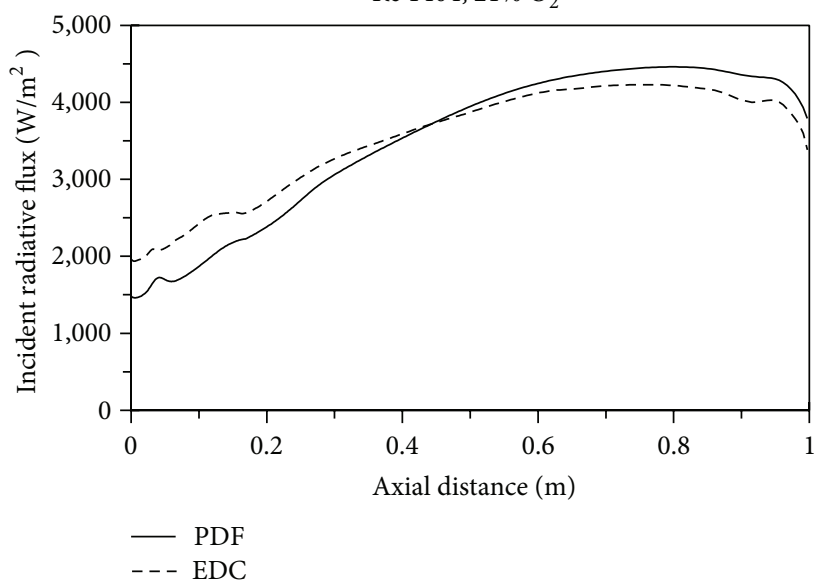

(a)

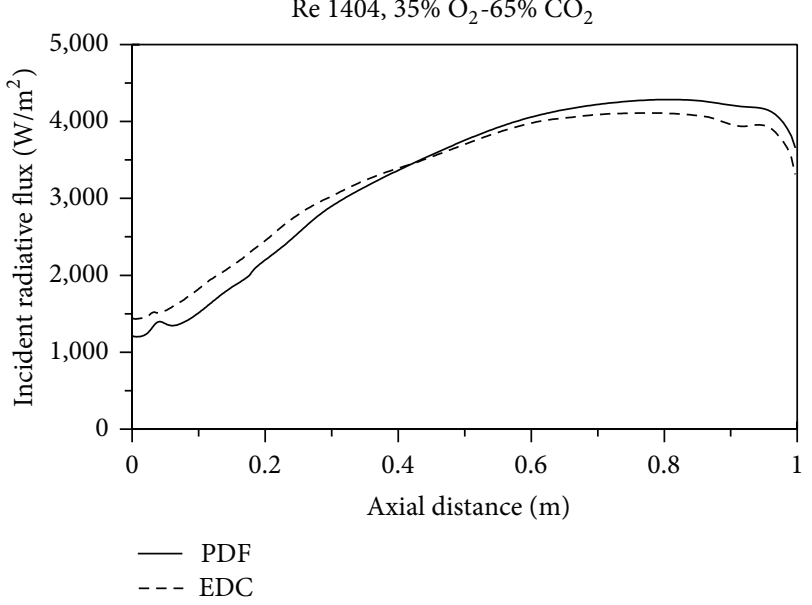

(b)

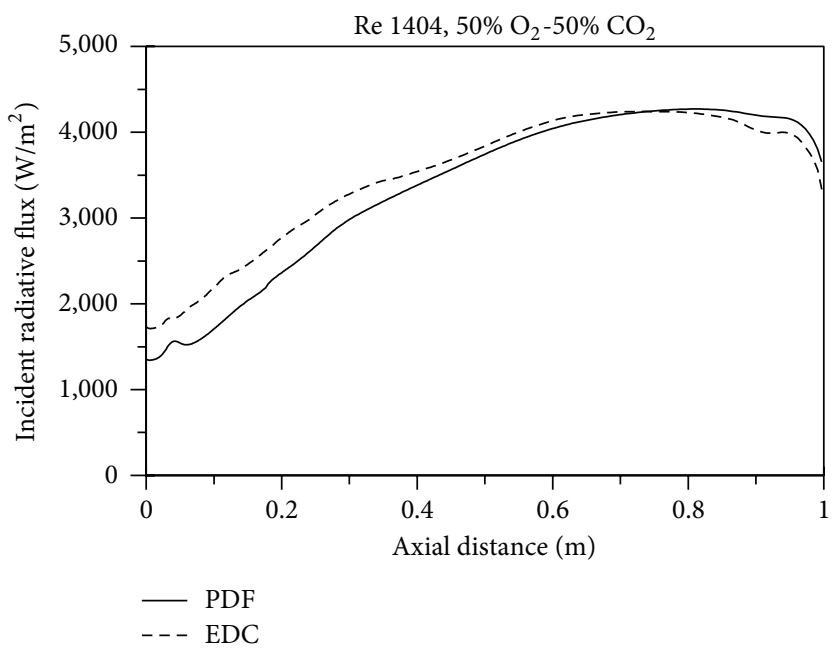

(c)

FIGURE 11: Variations in the incident radiative fluxes $\left(\right.$ in $\mathrm{W} / \mathrm{m}^{2}$ ) at the wall predicted by the different chemistry models: (a) Re 1404, methaneair flame; (b) Re 1404, oxy-methane flame $\left(35 \% \mathrm{O}_{2}-65 \% \mathrm{CO}_{2}\right)$; (c) Re 1404, oxy-methane flame $\left(50 \% \mathrm{O}_{2}-50 \% \mathrm{CO}_{2}\right)$.

of the net radiative flux lost through the boundaries of the volume. The volume of the furnace is $0.098 \mathrm{~m}^{3}$ whereas the area of the sidewall of the furnace along which the incident radiative fluxes are reported is $1.1 \mathrm{~m}^{2}$. Due to a more than 10 -fold difference in the magnitude of these two numbers, a $60 \%$ variation in $Q_{R}$, for instance, will correspond to a $6 \%$ difference in the net radiative flux along the sidewall (since this variation gets distributed along the entire surface area). Therefore, the average variations in the surface incident radiative fluxes (which are obtained from the net radiative fluxes and the wall emission) shown in Figure 10 are about $10 \%$.

The variations in the incident radiative fluxes (in $\mathrm{W} / \mathrm{m}^{2}$ ) at the wall predicted from employing the EDC and PDF models chemistry models in the simulations are shown in Figure 11. The Perry (5 gg) model was employed to estimate the radiative properties. Similar to the variations in $Q_{R}$ observed in Tables 3 and 4, the selection of the WSGG model has a greater impact on the incident radiative flux predictions than deciding on the chemistry modeling option between the PDF and EDC methods.

3.8. $Q_{R}$ Variations by Temperature Region. In order to isolate the region within the reactor that is the source of the strongest variations among the WSGG models, the following postprocessing methodology was employed on the fully converged flame fields after the radiative source terms had been estimated throughout the domain. The computational domain of the flames was divided into three regions: temperatures less than $500 \mathrm{~K}$ (representative of temperatures outside the range of validity of the WSGGM examined in this study), temperatures between $500 \mathrm{~K}$ and $800 \mathrm{~K}$ (corresponding to temperatures outside the flame consisting mainly of postcombustion gases whose gas composition and the $\mathrm{H}_{2} \mathrm{O} / \mathrm{CO}_{2}$ ratios are nearly homogeneous), and temperatures greater than $800 \mathrm{~K}$. The contributions of the different temperature 
TABLE 5: Contributions of different temperature ranges to the volume integrated radiative source (in W) $\left(Q_{R}\right)$ for the Re 1404 and $R e 2340$ flames investigated in this study (sensitivity to WSGG models).

\begin{tabular}{|c|c|c|c|c|c|c|}
\hline & EWBM (5 gg) & Perry (5 gg) & EM2C (5 gg) & HITEMP 2010 (5 gg) & Max \% variation & $\mathrm{H}_{2} \mathrm{O} / \mathrm{CO}_{2}$ \\
\hline \multicolumn{7}{|c|}{ PDF, Re $1404, T<500 \mathrm{~K}$} \\
\hline $21 \% \mathrm{O}_{2}$ & 23 & 19 & 22 & 18 & 22 & 1.94 \\
\hline $35 \% \mathrm{O}_{2}$ & 123 & 155 & 136 & 121 & 22 & 0.05 \\
\hline $50 \% \mathrm{O}_{2}$ & 175 & 180 & 187 & 182 & 6 & 0.04 \\
\hline \multicolumn{7}{|c|}{ PDF, Re 2340, $T<500 \mathrm{~K}$} \\
\hline $21 \% \mathrm{O}_{2}$ & 34 & 31 & 38 & 35 & 18 & 1.93 \\
\hline $35 \% \mathrm{O}_{2}$ & 207 & 198 & 239 & 209 & 17 & 0.02 \\
\hline $50 \% \mathrm{O}_{2}$ & 252 & 230 & 268 & 246 & 14 & 0.02 \\
\hline \multicolumn{7}{|c|}{ PDF, Re $1404,500 \mathrm{~K}<T<800 \mathrm{~K}$} \\
\hline $21 \% \mathrm{O}_{2}$ & -546 & -504 & -612 & -794 & -58 & 2.00 \\
\hline $35 \% \mathrm{O}_{2}$ & -521 & -481 & -862 & -522 & -79 & 0.17 \\
\hline $50 \% \mathrm{O}_{2}$ & -498 & -443 & -820 & -462 & -85 & 0.13 \\
\hline \multicolumn{7}{|c|}{ PDF, Re $2340,500 \mathrm{~K}<T<800 \mathrm{~K}$} \\
\hline $21 \% \mathrm{O}_{2}$ & -807 & -821 & -907 & -1177 & -46 & 2.00 \\
\hline $35 \% \mathrm{O}_{2}$ & -1122 & -873 & -1609 & -1279 & -84 & 0.20 \\
\hline $50 \% \mathrm{O}_{2}$ & -1037 & -745 & -1456 & -1121 & -95 & 0.26 \\
\hline \multicolumn{7}{|c|}{ PDF, Re $1404, T>800 \mathrm{~K}$} \\
\hline $21 \% \mathrm{O}_{2}$ & -278 & -337 & -299 & -313 & -21 & 2.09 \\
\hline $35 \% \mathrm{O}_{2}$ & -342 & -429 & -463 & -387 & -35 & 0.23 \\
\hline $50 \% \mathrm{O}_{2}$ & -490 & -518 & -644 & -562 & -31 & 0.18 \\
\hline \multicolumn{7}{|c|}{ PDF, Re $2340, T>800 \mathrm{~K}$} \\
\hline $21 \% \mathrm{O}_{2}$ & -1098 & -1099 & -1192 & -1376 & -25 & 2.02 \\
\hline $35 \% \mathrm{O}_{2}$ & -1134 & -1049 & -1434 & -1140 & -37 & 0.22 \\
\hline $50 \% \mathrm{O}_{2}$ & -1361 & -1279 & -1667 & -1370 & -30 & 0.27 \\
\hline
\end{tabular}

ranges to the $Q_{R}$ in the PDF model simulations are summarized in Table 5 along with the average $\mathrm{H}_{2} \mathrm{O} / \mathrm{CO}_{2}$ ratios in the region. In other words, the results reported in Table 3 are broken down by different temperature regions in Table 5.

Figure 12 shows the corresponding variations in $Q_{R}$ among the WSGG models in the calculations that employed the EDC chemistry model. In Figure 12, the maximum percentage variations in $Q_{R}$ were determined to be $36 \%, 63 \%$, and $59 \%$ for the flames with the oxidizers: air, $35 \% \mathrm{O}_{2}$ $65 \% \mathrm{CO}_{2}$ and $50 \% \mathrm{O}_{2}-50 \% \mathrm{CO}_{2}$, respectively. Therefore, the variations in $Q_{R}$ were seen to be independent of the chemistry model employed in the simulations as well. However, from Table 5 and Figure 12 we see that the maximum variations among the WSGG models are observed to originate from the $500 \mathrm{~K}-800 \mathrm{~K}$ temperature range corresponding to postcombustion gases in the upper sections of the furnace.

While all of the WSGG models employed in this study have been validated through comparisons against benchmark/line-by-line (LBL) data for prototypical problems [12, 13,38 ] in the general temperature range $1000 \mathrm{~K}-2000 \mathrm{~K}$, our results demonstrate that variations among the underlying spectroscopic databases employed in their formulation can result in corresponding variations in the radiative transfer predictions in coupled combustion calculations. Lallemant et al. [42] observed a significant variation in the emissivity predictions due to the differences in spectroscopic/model databases employed in the emissivity calculations. Recently, a similar evaluation at conditions representative of oxycombustion scenarios was carried out by Becher et al. [43], however, at constant $\mathrm{H}_{2} \mathrm{O} / \mathrm{CO}_{2}$ ratios and constant temperature conditions $(1073 \mathrm{~K}-2073 \mathrm{~K})$. By comparing the total emissivities predicted by different WSGG model formulations against those obtained from the HITEMP 2010 spectroscopic database, they determined the WSGGM formulation of Johansson et al. [44] to be the most versatile and computationally efficient model, followed by the older model of Johansson et al. [10]. A comparison against the updated WSGGM parameters based on the RADCAL SNB that was published in Krishnamoorthy [12] was not carried out likely due to the close timing of both these publications. However, in a more recent study, Kangwanpongpan et al. [13] published WSGGM correlations based on fitting the coefficients to total emissivities from the HITEMP 2010 LBL database. In their study, the radiative heat fluxes and its divergence were obtained from line-by-line (LBL) calculations for test cases encompassing wide ranges of composition nonhomogeneities, nonisothermal media, and path lengths and were treated as benchmarks. Their proposed WSGGM was then demonstrated to be the most accurate formulation when compared against the benchmarks with large errors associated with the EM2C SNB based model of Johansson et al. [44].

The laminar oxy-methane flames in enclosed environments (such as those examined in this study) as a result of the oxygen enriched combustion environment were seen to 


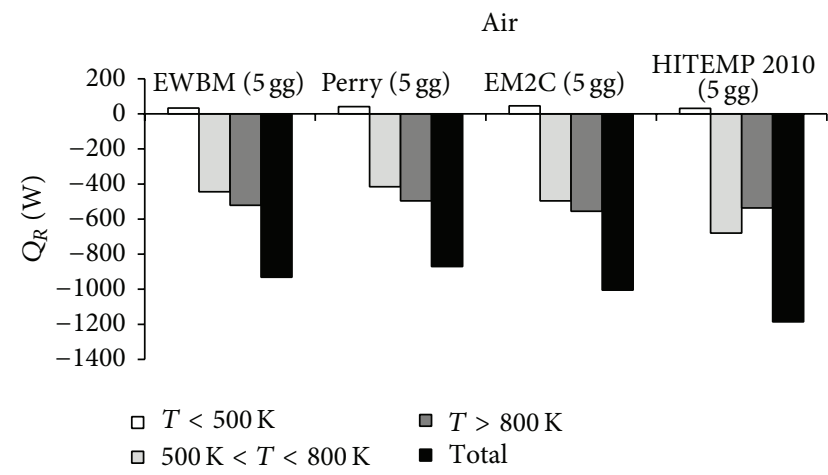

(a)

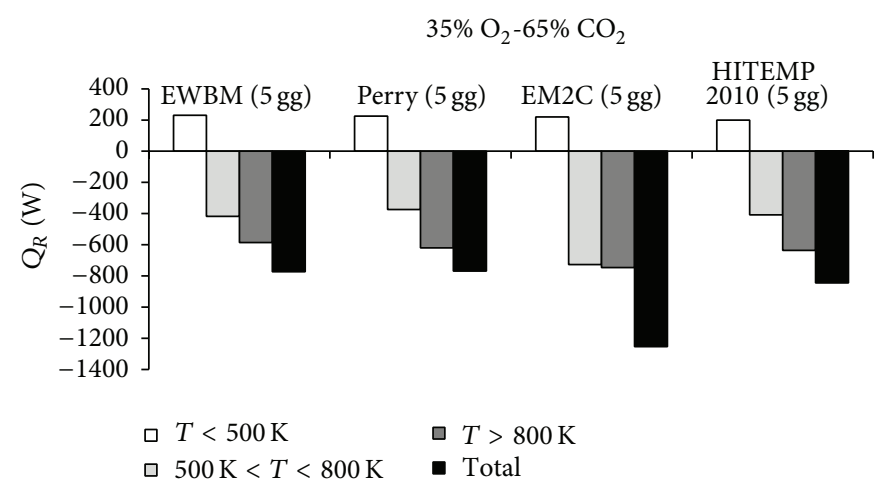

(b)

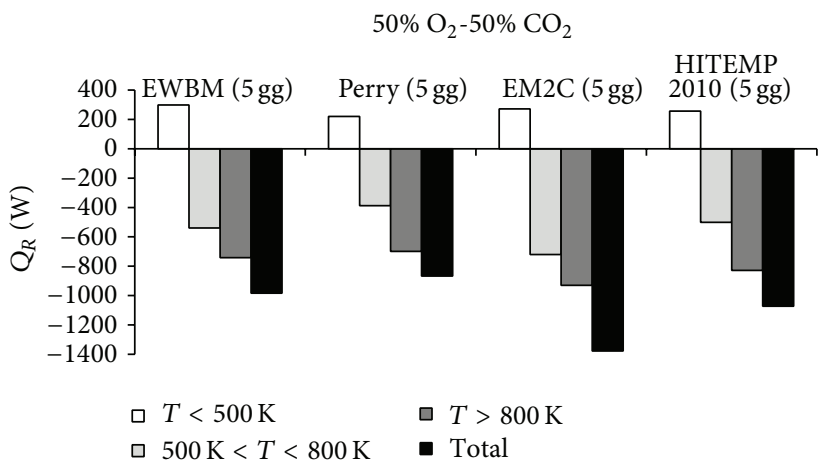

(c)

FiguRE 12: Contributions of different temperature ranges to the volume integrated radiative source (in W) $\left(Q_{R}\right)$ when the flames were simulated using the EDC chemistry model (sensitivity to WSGG models): (a) Re 1404, methane-air flame; (b) Re 1404, oxy-methane flame $\left(35 \% \mathrm{O}_{2}-65 \% \mathrm{CO}_{2}\right) ;(\mathrm{c}) \mathrm{Re} 1404$, oxy-methane flame $\left(50 \% \mathrm{O}_{2}-50 \% \mathrm{CO}_{2}\right)$.

attain temperatures greater than $2000 \mathrm{~K}$ within the flame and by virtue of their shorter flame lengths, encounter sharper temperature and species concentration gradients, and result in reactor temperatures that are lower than $800 \mathrm{~K}$ in a large portion of the reactor volume (cf. Figures 2-5). Since these extremes are well outside the range of conditions examined in the studies of Becher et al. [43] and Kangwanpongpan et al. [13] and total emissivities were compared in one study [22] while directionally integrated quantities (radiative flux and its divergence) was compared in the other [13], this study demonstrates the variations in radiative transfer predictions that might result from employing different WSGGM formulations in multiphysics CFD simulations of flames.

The different WSGGM considered in this study presents model coefficients for different $\mathrm{H}_{2} \mathrm{O} / \mathrm{CO}_{2}$ ratios encompassing methane-air and oxy-methane combustion scenarios. However, as seen in Table 5, the nonhomogeneity in the $\mathrm{H}_{2} \mathrm{O} / \mathrm{CO}_{2}$ ratio within the flame (corresponding to temperatures $>800 \mathrm{~K}$ ) or employing the WSGG models outside the lower temperature limit of their validity (temperatures < $500 \mathrm{~K}$ ) result in only $20-40 \%$ variations among the model predictions. However, within the homogeneous region of postcombustion gases encompassing the temperature range $500 \mathrm{~K}-800 \mathrm{~K}$, maximum variations in $Q_{R}$ among the models are observed. Furthermore, this region contributes to more than $60 \%$ and $45 \%$ of the total $Q_{R}$ in the Re 1404 and Re 2340 oxy-flames, respectively. Previous studies have not assessed the accuracies of the different WSGG formulations in this temperature region against LBL data since this temperature range is generally not of interest in industrial scenarios. However, in lab-scale enclosed flames where large regions of low temperatures $(<800 \mathrm{~K})$ are encountered, modelers must exercise caution when validating model predictions against experimental measurements of radiative transfer since the choice of the validated radiative property models by themselves can cause significant variations in the predictions.

\section{Conclusions}

A knowledge gap currently exists in our understanding of radiative heat transfer from oxy-methane flames particularly at different $\mathrm{O}_{2}-\mathrm{CO}_{2}$ dilution ratios employed in the oxidizer stream to regulate the flame temperature and radiative fluxes. The peak flame temperature increases, but the flame length decreases, with an increase in $\mathrm{O}_{2}$ concentration in the oxidizer stream. These two factors not only have opposing impacts on the radiative heat fluxes and flame radiant fractions but also can alter the wall radiative flux profiles and the location of the peak fluxes. Further, recent experimental observations have revealed that similar heat flux distributions and flame 
radiant fraction values were obtained during combustion of methane in air as well as $35 \% \mathrm{O}_{2}-65 \% \mathrm{CO}_{2}$ as the oxidizers. However, these values increased with an increase in oxidizer $\mathrm{O}_{2}$ concentration which was attributed to higher peak flame temperatures and enhanced soot formation rates. A goal of this study was to garner insights into these experimental observations through CFD simulations of the experimental conditions employing chemistry and radiative property models that have previously been deemed to be accurate for simulating these oxy-combustion scenarios. Furthermore, this study also aims to improve estimates of the flame radiant power by providing more complete descriptions of the flame shape and the spatial variations in temperature and gas concentrations and highlight the prediction sensitivities to the choice of chemistry and radiative property modeling options employed in the simulations.

The chemistry was modeled employing the nonadiabatic extension of the equilibrium probability density function based mixture fraction model, the Eddy dissipation concept (EDC) employing a 41-step detailed chemistry mechanism, and two-step global finite rate chemistry (FR) model with modified rate constants proposed to work well under oxymethane conditions. The gas-phase radiative properties were estimated employing different formulations of the weightedsum-of-gray-gases models (WSGGM) that were based on four different spectroscopic/model databases. Measurements from and numerical predictions of methane-air flames are also included for comparison, with the simulations performed employing models appropriate for methane combustion in air. Based on the results from this study the following conclusions may be drawn.

(1) Consistent with experimental observations, the mixture fraction and EDC models correctly predicted a decrease in flame length, an increase in peak flame temperature, and an increase in $\mathrm{OH}$ concentration, with an increase in $\mathrm{O}_{2}$ concentration in the oxidizer stream.

(2) The mixture fraction and EDC model predictions were also in reasonable agreement against the experimental measurements of $\mathrm{O}_{2}, \mathrm{CO}_{2}$, and gas temperatures outside the flames at all oxidizer compositions. However, the global finite rate chemistry model with the modified rate constants, while predicting the $\mathrm{CO}_{2}$ and $\mathrm{O}_{2}$ concentrations well in the $35 \% \mathrm{O}_{2}-65 \% \mathrm{CO}_{2}$ oxy-flame, deviated from their measured values in the $50 \% \mathrm{O}_{2}-50 \% \mathrm{CO}_{2}$ oxy-flame. This is likely due to the fact that the refined kinetic parameters have not been validated for flames where oxygen concentration in the oxidizer stream was as high as $50 \%$.

(3) The global finite rate chemistry model by virtue of limited dissociation predicted higher temperature than the mixture fraction and EDC approaches. In spite of differences in the temperature predictions between the EDC and mixture fraction models within the flames at lower axial locations, the flame radiant power estimates between these two models varied by less than $10 \%$. This was attributed to facts that the EDC model predicted higher flame temperatures but shorter flames than the mixture fraction model, temperatures prediction differences between the models were minimized in regions outside the flame and at higher axial locations, and more than $50 \%$ of the contribution to the radiant power was from these regions outside the flame where the temperature predictions between the models were nearly identical.

(4) Differences in the spectroscopic/model databases employed in the WSGGM formulations resulted in more than a $60 \%$ variation in the volume integrated radiative source term predictions in all of the oxyflames. The corresponding variations in the methaneair flames were about $35 \%$. These variations were found to be independent of the fuel Reynolds numbers (Re 1404, Re 2340) and the chemistry models (EDC, mixture fraction) employed in the simulations. These variations in the radiant fraction predictions among the WSGG models were identified to be the strongest in the upper sections of the reactor where the postcombustion gas temperature was between $500 \mathrm{~K}$ and $800 \mathrm{~K}$ and the gas compositions were nearly homogeneous.

(5) While all of the WSGG models employed in this study have been validated through comparisons against benchmark/line-by-line (LBL) data for prototypical problems in the general temperature range $1000 \mathrm{~K}-$ $2000 \mathrm{~K}$, our results therefore demonstrate that at lower temperatures $(500 \mathrm{~K}-800 \mathrm{~K})$ significant prediction variations among these models can arise due to differences in the underlying spectroscopic databases employed in their formulation and the emissivity curve fitting procedure. The variations in radiative transfer predictions resulting from these variations would depend on the fractional contribution from this temperature range to the overall radiative heat transfer. This fractional contribution can be quite significant $(>50 \%)$ from small laminar to transitional flames in enclosed domains as observed in this study.

(6) These variations in the radiative source term predictions among the WSGG models made it difficult to numerically ascertain the trends in radiant fraction variations with the changes in the oxygen concentration in the oxidizer stream. The EWBM $(5 \mathrm{gg})$ and Perry (5 gg) models in general predicted similar flame radiant fractions at all three oxidizer compositions. These results are generally in agreement with the observations of Ditaranto and Oppelt [19] who observed similar heat flux distributions and radiant fraction values for combustion in air as well as $35 \% \mathrm{O}_{2}-65 \% \mathrm{CO}_{2}$ oxidizers. The EM2C (5 gg) model predicted a significant increase in radiant fraction with the increase in oxygen composition in the oxidizer stream whereas the HITEMP 2010 (5 gg) model predicted a decrease in radiant fraction in the oxyflames. 
(7) While these variations in the radiative source term predictions did not significantly impact the gas temperature predictions (the maximum temperature variation was generally within $25 \mathrm{~K}$ among the different WSGGM), they did have a bearing on the incident radiative flux (that would be measured by a sensor) predictions at the walls through the overall radiative energy balance.

(8) In the high temperature regions within the flame $(T>$ $800 \mathrm{~K})$ that exhibited strong temperature gradients and sharp variations in the $\mathrm{H}_{2} \mathrm{O} / \mathrm{CO}_{2}$ ratios, the corresponding variations in the volume integrated radiative source term predictions among the WSGGM were considerably less. Therefore, when the radiation is dominated by high temperature gases $(>1000 \mathrm{~K})$, the incident radiative fluxes at the walls may not be very sensitive to the choice of WSGGM employed in the simulation as noted in previous simulations of semi-industrial scale furnaces [27].

(9) As a result of the low soot volume fractions predicted in the simulations, the effect of soot on the radiative transfer predictions and conclusions reported in this study was determined to be negligible.

\section{Conflict of Interests}

The authors declare that there is no conflict of interests regarding the publication of this paper.

\section{Acknowledgments}

This research was partly funded by a ND EPSCoR New Faculty Start-Up Award to Dr. Gautham Krishnamoorthy. Mario Ditaranto was funded by the BIGCCS Centre performed under the Norwegian Research Program Centers for Environment-Friendly Energy Research (FME) and acknowledges the following partners for their contributions: ConocoPhillips, Gassco, Shell, Statoil, TOTAL, GDF SUEZ, and the Research Council of Norway (193816/S60).

\section{References}

[1] B. J. P. Buhre, L. K. Elliott, C. D. Sheng, R. P. Gupta, and T. F. Wall, "Oxy-fuel combustion technology for coal-fired power generation," Progress in Energy and Combustion Science, vol. 31, no. 4, pp. 283-307, 2005.

[2] T. Wall, R. Stanger, and S. Santos, "Demonstrations of coalfired oxy-fuel technology for carbon capture and storage and issues with commercial deployment," International Journal of Greenhouse Gas Control, vol. 5, supplement 1, pp. S5-S15, 2011.

[3] P. Glarborg and L. L. B. Bentzen, "Chemical effects of a high $\mathrm{CO}_{2}$ concentration in oxy-fuel combustion of methane," Energy \& Fuels, vol. 22, no. 1, pp. 291-296, 2008.

[4] A. Amato, B. Hudak, P. D'Souza et al., "Measurements and analysis of $\mathrm{CO}$ and $\mathrm{O}_{2}$ emissions in $\mathrm{CH}_{4} / \mathrm{CO}_{2} / \mathrm{O}_{2}$ flames," Proceedings of the Combustion Institute, vol. 33, no. 2, pp. 33993405, 2011.

[5] F. S. Liu, H. S. Guo, G. J. Smallwood, and Ö. L. Gülder, "The chemical effects of carbon dioxide as an additive in an ethylene diffusion flame: implications for soot and NOx formation," Combustion and Flame, vol. 125, no. 1-2, pp. 778-787, 2001.

[6] K. C. Oh and H. D. Shin, "The effect of oxygen and carbon dioxide concentration on soot formation in non-premixed flames," Fuel, vol. 85, no. 5-6, pp. 615-624, 2006.

[7] H. Watanabe, T. Marumo, and K. Okazaki, "Effect of $\mathrm{CO}_{2}$ reactivity on $\mathrm{NO}_{x}$ formation and reduction mechanisms in $\mathrm{O}_{2} /$ $\mathrm{CO}_{2}$ combustion," Energy and Fuels, vol. 26, no. 2, pp. 938-951, 2012.

[8] L. Chen, S. Z. Yong, and A. F. Ghoniem, "Oxy-fuel combustion of pulverized coal: characterization, fundamentals, stabilization and CFD modeling," Progress in Energy and Combustion Science, vol. 38, no. 2, pp. 156-214, 2012.

[9] P. Edge, M. Gharebaghi, R. Irons et al., "Combustion modelling opportunities and challenges for oxy-coal carbon capture technology," Chemical Engineering Research and Design, vol. 89, no. 9, pp. 1470-1493, 2011.

[10] R. Johansson, K. Andersson, B. Leckner, and H. Thunman, "Models for gaseous radiative heat transfer applied to oxy-fuel conditions in boilers," International Journal of Heat and Mass Transfer, vol. 53, no. 1-3, pp. 220-230, 2010.

[11] C. Yin, L. C. R. Johansen, L. A. Rosendahl, and S. K. Kær, "New weighted sum of gray gases model applicable to computational fluid dynamics (CFD) modeling of oxy-fuel combustion: derivation, validation, and implementation," Energy and Fuels, vol. 24, no. 12, pp. 6275-6282, 2010.

[12] G. Krishnamoorthy, "A new weighted-sum-of-gray-gases model for oxy-combustion scenarios," International Journal of Energy Research, vol. 37, no. 14, pp. 1752-1763, 2013.

[13] T. Kangwanpongpan, F. H. R. França, R. C. Da Silva, P. S. Schneider, and H. J. Krautz, "New correlations for the weightedsum-of-gray-gases model in oxy-fuel conditions based on HITEMP 2010 database," International Journal of Heat and Mass Transfer, vol. 55, no. 25-26, pp. 7419-7433, 2012.

[14] C. K. Westbrook and F. L. Dryer, "Simplified reaction mechanisms for the oxidation of hydrocarbon fuels in flames," Combustion Science and Technology, vol. 27, no. 1-2, pp. 31-43, 1981.

[15] W. P. Jones and R. P. Lindstedt, "Global reaction schemes for hydrocarbon combustion," Combustion and Flame, vol. 73, no. 3, pp. 233-249, 1988.

[16] J. Andersen, C. L. Rasmussen, T. Giselsson, and P. Glarborg, "Global combustion mechanisms for use in CFD modeling under oxy-fuel conditions," Energy and Fuels, vol. 23, no. 3, pp. 1379-1389, 2009.

[17] C. Yin, L. A. Rosendahl, and S. K. Kær, "Chemistry and radiation in oxy-fuel combustion: a computational fluid dynamics modeling study," Fuel, vol. 90, no. 7, pp. 2519-2529, 2011.

[18] S. Hjärtstam, F. Normann, K. Andersson, and F. Johnsson, "Oxy-fuel combustion modeling: performance of global reaction mechanisms," Industrial and Engineering Chemistry Research, vol. 51, no. 31, pp. 10327-10337, 2012.

[19] M. Ditaranto and T. Oppelt, "Radiative heat flux characteristics of methane flames in oxy-fuel atmospheres," Experimental Thermal and Fluid Science, vol. 35, no. 7, pp. 1343-1350, 2011.

[20] W. L. Grosshandler, "RADCAL—a narrow-band model for radiation calculations in a combustion environment," NIST Technical Note 1402, 1993.

[21] H. Abdul-Sater and G. Krishnamoorthy, "An assessment of radiation modeling strategies in simulations of laminar to transitional, oxy-methane, diffusion flames," Applied Thermal Engineering, vol. 61, no. 2, pp. 507-518, 2013. 
[22] V. Becher, J.-P. Bohn, P. Dias, and H. Spliethoff, "Validation of spectral gas radiation models under oxyfuel conditionspart B: natural gas flame experiments," International Journal of Greenhouse Gas Control, vol. 5, no. 1, pp. S66-S75, 2011.

[23] ANSYS FLUENT User's Guide, Version 12, ANSYS Inc., Canonsburg, Pa, USA, 2009.

[24] R. Prieler, M. Demuth, D. Spoljaric, and C. Hochenauer, "Evaluation of a steady flamelet approach for use in oxy-fuel combustion," Fuel, vol. 118, pp. 55-68, 2014.

[25] M. A. Nemitallah and M. A. Habib, "Experimental and numerical investigations of an atmospheric diffusion oxy-combustion flame in a gas turbine model combustor," Applied Energy, vol. 111, pp. 401-415, 2013.

[26] C. Galletti, G. Coraggio, and L. Tognotti, "Numerical investigation of oxy-natural-gas combustion in a semi-industrial furnace: validation of CFD sub-models," Fuel, vol. 109, pp. 445460, 2013.

[27] Z. Wheaton, D. Stroh, G. Krishnamoorthy, M. Sami, S. Orsino, and P. Nakod, "A comparative study of gray and non-gray methods of computing gas absorption coefficients and its effect on the numerical predictions of oxy-fuel combustion," Industrial Combustion, Article ID 201302, pp. 1-14, 2013.

[28] G. Krishnamoorthy, "A new weighted-sum-of-gray-gases model for $\mathrm{CO}_{2}-\mathrm{H}_{2} \mathrm{O}$ gas mixtures," International Communications in Heat and Mass Transfer, vol. 37, no. 9, pp. 1182-1186, 2010.

[29] K. Bhadraiah and V. Raghavan, "Numerical simulation of laminar co-flow methane-oxygen diffusion flames: effect of chemical kinetic mechanisms," Combustion Theory and Modelling, vol. 15, no. 1, pp. 23-46, 2011.

[30] G. Kim, Y. Kim, and Y.-J. Joo, "Conditional moment closure for modeling combustion processes and structure of oxy-natural gas flame," Energy and Fuels, vol. 23, no. 9, pp. 4370-4377, 2009.

[31] B. A. V. Bennett, Z. Cheng, R. W. Pitz, and M. D. Smooke, "Computational and experimental study of oxygen-enhanced axisymmetric laminar methane flames," Combustion Theory and Modelling, vol. 12, no. 3, pp. 497-527, 2008.

[32] J. P. van Doormaal and G. D. Raithby, "Enhancements of the simple method for predicting incompressible fluid flows," Numerical Heat Transfer, vol. 7, no. 2, pp. 147-163, 1984.

[33] S. V. Patankar, Numerical Heat Transfer and Fluid Flow, Hemisphere, Washington, DC, USA, 1980.

[34] B. P. Leonard and S. Mokhtari, "ULTRA-SHARP non-oscillatory convection schemes for high-speed steady multidimensional flow," NASATM1-2568 (ICOMP-90-12), NASA Lewis Research Center, 1990.

[35] A. De, E. Oldenhof, P. Sathiah, and D. J. E. M. Roekaerts, "Numerical simulation of delft-jet in-hot-coflow (DJHC) flames using the eddy dissipation concept model for turbulencechemistry interaction," Flow, Turbulence and Combustion, vol. 87, no. 4, pp. 537-567, 2011.

[36] A. Shiehnejadhesar, R. Mehrabian, R. Scharler, G. M. Goldin, and I. Obernberger, "Development of a gas phase combustion model suitable for low and high turbulence conditions," Fuel, vol. 126, pp. 177-187, 2014.

[37] M. D. Smooke, Reduced Kinetic Mechanisms and Asymptotic Approximation for Methane-Air Flames: a Topical Volume, vol. 384 of Lecture Notes in Physics, Springer, Berlin, Germany, 1991.

[38] H. Chu, F. Liu, and H. Zhou, "Calculations of gas thermal radiation transfer in one-dimensional planar enclosure using LBL and SNB models," International Journal of Heat and Mass Transfer, vol. 54, no. 21-22, pp. 4736-4745, 2011.
[39] S. Inge and M. Ditaranto, "Soot formation in diffusion flames in oxy-fuel atmospheres," 2015, http://www.sintef.no/.

[40] S. J. Brookes and J. B. Moss, "Predictions of soot and thermal radiation properties in confined turbulent jet diffusion flames," Combustion and Flame, vol. 116, no. 4, pp. 486-503, 1999.

[41] G. Krishnamoorthy, S. Borodai, R. Rawat, J. Spinti, and P. J. Smith, "Numerical modeling of radiative heat transfer in pool fire simulations," in Proceedings of the ASME International Mechanical Engineering Congress and Exposition (IMECE '05), pp. 327-337, American Society of Mechanical Engineers, Orlando, Fla, USA, November 2005.

[42] N. Lallemant, A. Sayre, and R. Weber, "Evaluation of emissivity correlations for $\mathrm{H}_{2} \mathrm{O}-\mathrm{CO}_{2}-\mathrm{N}_{2} /$ AIR mixtures and coupling with solution methods of the radiative transfer equation," Progress in Energy and Combustion Science, vol. 22, no. 6, pp. 543-574, 1996.

[43] V. Becher, A. Goanta, and H. Spliethoff, "Validation of spectral gas radiation models under oxyfuel conditions-part C: validation of simplified models," International Journal of Greenhouse Gas Control, vol. 11, pp. 34-51, 2012.

[44] R. Johansson, B. Leckner, K. Andersson, and F. Johnsson, "Account for variations in the $\mathrm{H}_{2} \mathrm{O}$ to $\mathrm{CO}_{2}$ molar ratio when modelling gaseous radiative heat transfer with the weightedsum-of-grey-gases model," Combustion and Flame, vol. 158, no. 5, pp. 893-901, 2011. 

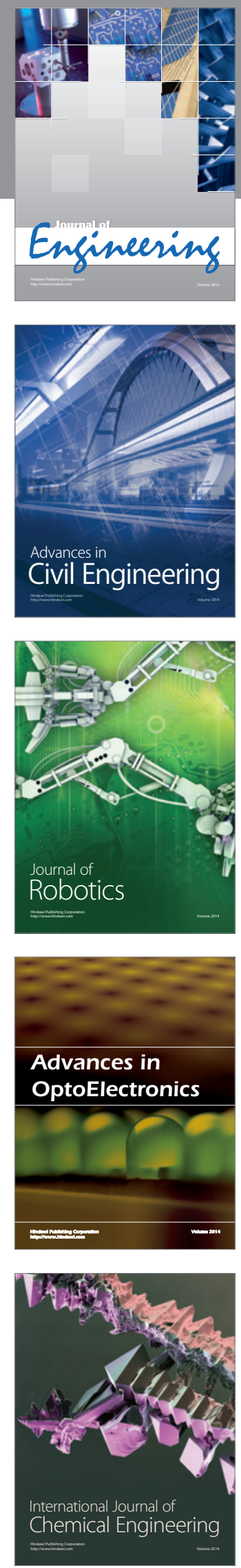

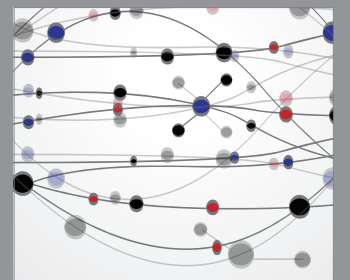

The Scientific World Journal
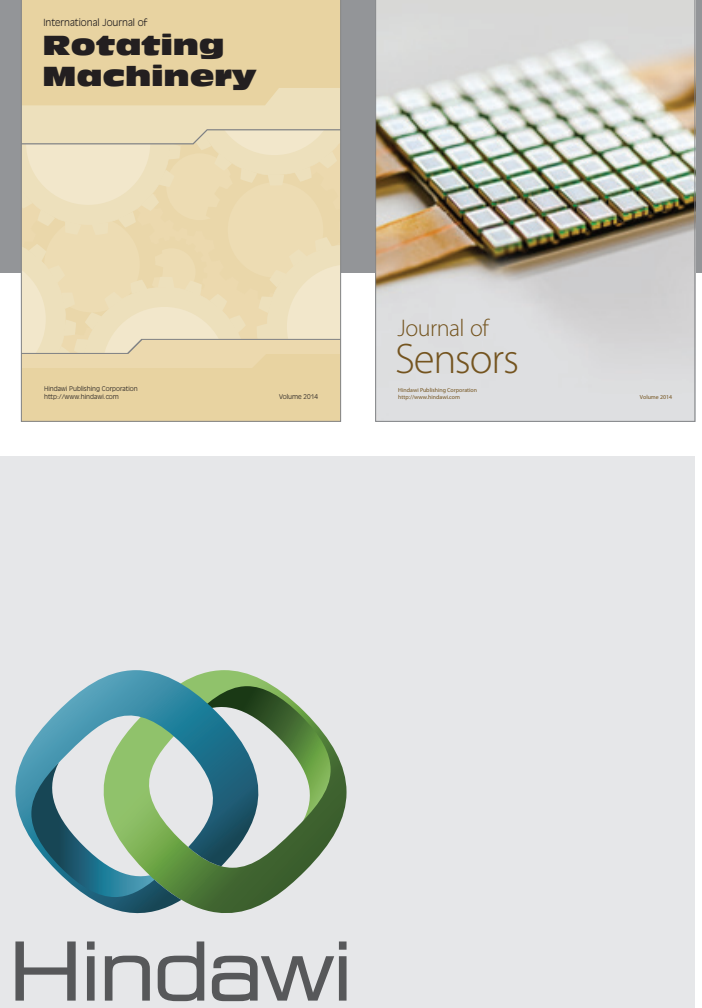

Submit your manuscripts at http://www.hindawi.com
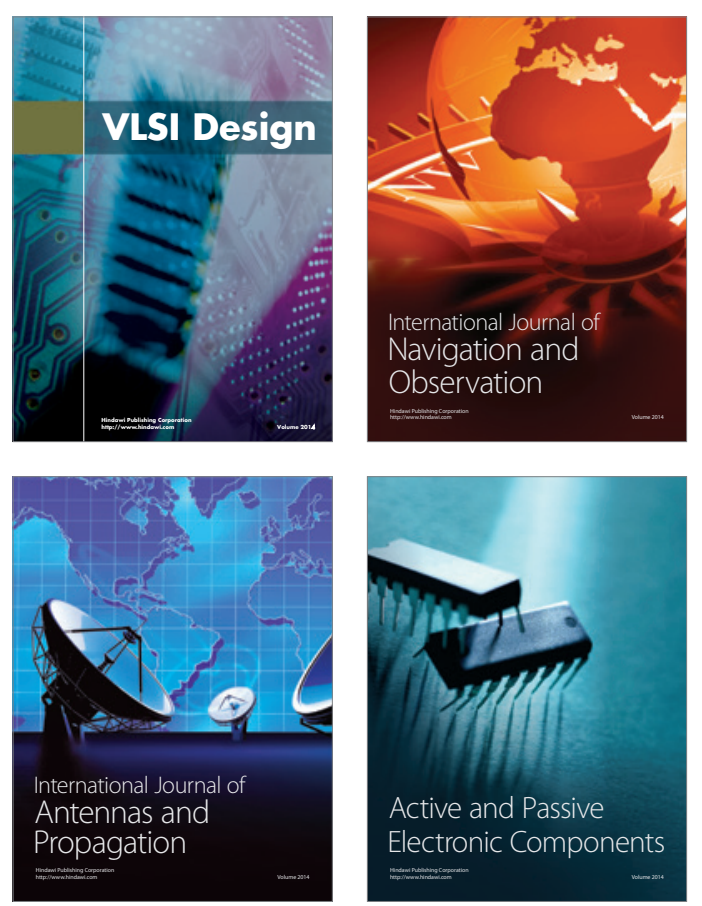
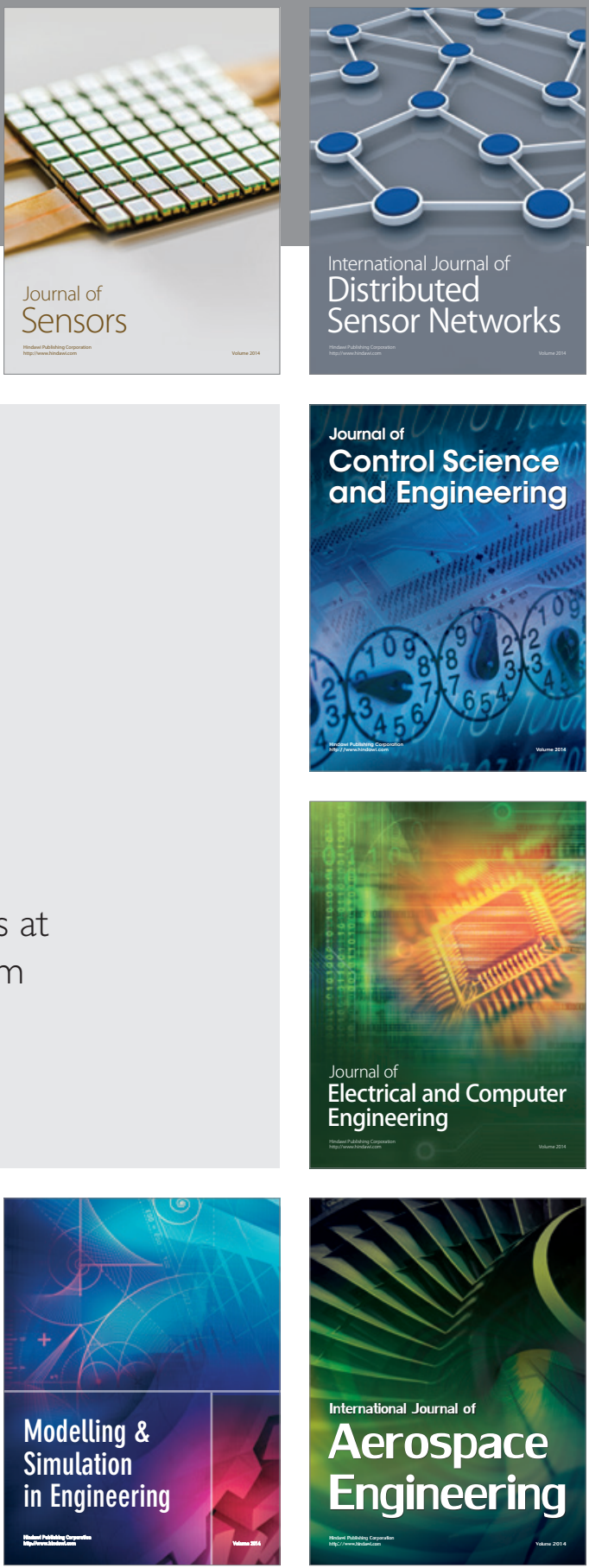

Journal of

Control Science

and Engineering
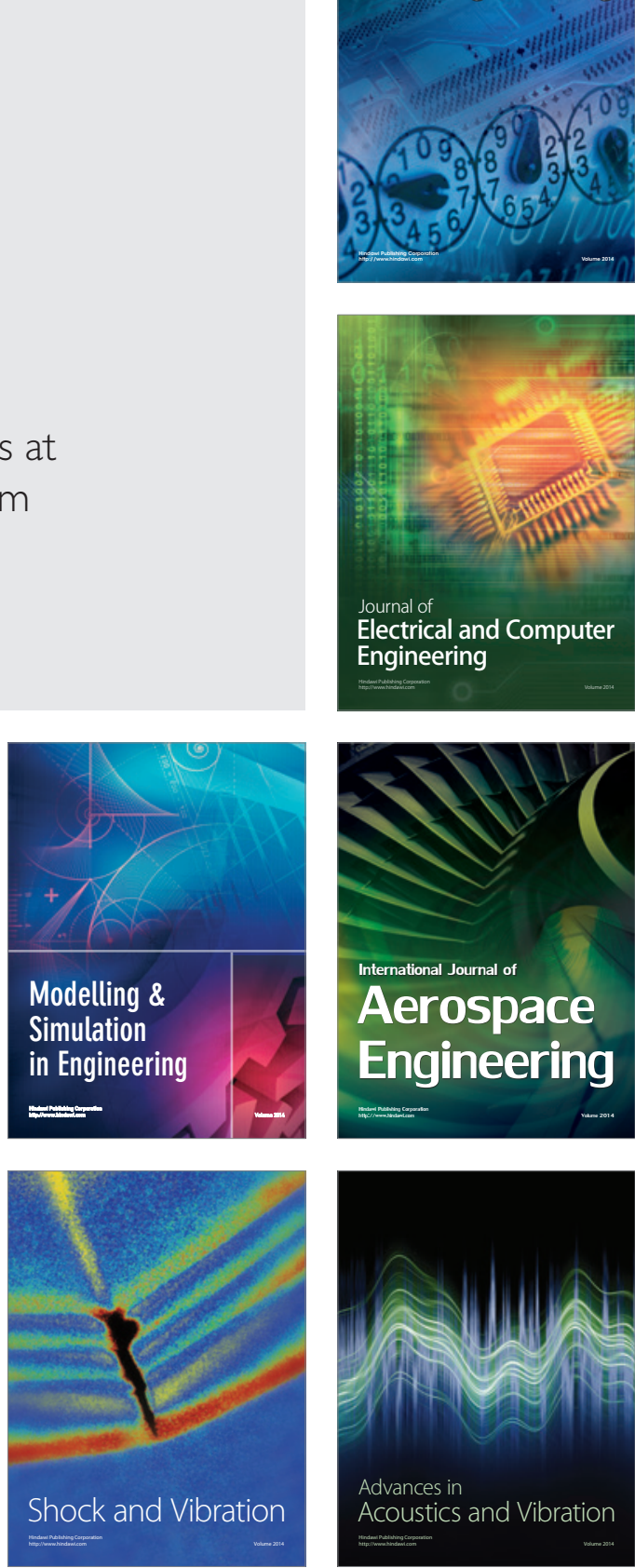